Full Length Article

\title{
Design and characterization of eutectic refractory high entropy alloys
}

\author{
N. Yurchenko*, E. Panina, S. Zherebtsov, N. Stepanov \\ Laboratory of Bulk Nanostructured Materials, Belgorod National Research University, Belgorod 308015, Russia
}

\section{A R T I C L E I N F O}

\section{Keywords:}

Refractory high entropy alloys

CALPHAD

Eutectic structure

Mechanical properties

Deformation behavior

\begin{abstract}
A B S T R A C T
Eutectic alloys are natural in-situ composites with near-equilibrium structures, impressive strength-ductility tradeoff, and perfect castability. In the current study, novel eutectic Al-Cr-Nb-Ti-Zr refractory high entropy alloys (RHEAs) were designed using a CALPHAD (CALculation of PHAse Diagrams) approach. A starting $\mathrm{Nb}_{30} \mathrm{Ti}_{40} \mathrm{Zr}_{30}$ (at.\%) alloy was based on a single-phase bcc solid solution. Alloying with $\mathrm{Cr}$ and $\mathrm{Al}$ induced the formation of hypoeutectic $\left(\mathrm{Cr}_{20} \mathrm{Nb}_{30} \mathrm{Ti}_{40} \mathrm{Zr}_{10}, \mathrm{Al}_{15} \mathrm{Cr}_{20} \mathrm{Nb}_{15} \mathrm{Ti}_{40} \mathrm{Zr}_{10}, \mathrm{Al}_{23} \mathrm{Cr}_{20} \mathrm{Nb}_{15} \mathrm{Ti}_{32} \mathrm{Zr}_{10}\right)$, eutectic $\left(\mathrm{Al}_{28} \mathrm{Cr}_{20} \mathrm{Nb}_{15} \mathrm{Ti}_{27} \mathrm{Zr}_{10}\right)$, and hypereutectic $\left(\mathrm{Al}_{33} \mathrm{Cr}_{20} \mathrm{Nb}_{15} \mathrm{Ti}_{22} \mathrm{Zr}_{10}\right)$ structures due to the Laves phase precipitation. $\mathrm{Al}$ additions also resulted in the $\mathrm{B} 2$ ordering of the bcc phase and changing the Laves phase polytype from $\mathrm{C} 15$ (fcc) to $\mathrm{C} 14$ (hcp). A transfer from the single-phase to eutectic microstructure, connected with the Laves phase amount's growth, increased the alloys' compressive strength and the brittle-to-ductile transition temperature pronouncedly. Quantitative relationships between the Laves phase's volume fraction and the alloys' yield strength at different temperatures were established. Detailed analysis of eutectic alloy after plastic deformation at $800{ }^{\circ} \mathrm{C}$ demonstrated the stability of a lamellar B2/C14 Laves phase microstructure due to saving an initial orientation relationship (OR) of $(011)_{\mathrm{B} 2}||(10 \overline{1} 3)_{\mathrm{C} 14},[1 \overline{1} 1]_{\mathrm{B} 2}||[3 \overline{3} 0 \overline{1}]_{\mathrm{C} 14}$ ensuring a small lattice mismatch. The precipitation of a new phase with $\mathrm{a} \mathrm{D0}_{19}$ structure having the $(011)_{\mathrm{B} 2}\left\|(10 \overline{1} 3)_{\mathrm{C} 14}\right\|(0 \overline{2} 21)_{\mathrm{D} 019}$ OR was also revealed. The obtained findings demonstrate new approaches to design RHEAs with (nearly) eutectic structures and a promising balance of mechanical characteristics.
\end{abstract}

\section{Introduction}

High entropy alloys (HEAs) offer a new paradigm to design metallic alloys with salient properties [1-3]. Unlike traditional alloys, HEAs are usually comprised of five or more elements taken in nearly equiatomic concentrations. The need for equal fractions of each component stemmed from an idea of maximizing the mixing entropy to suppress the intermetallics' formation [1]. However, the role of mixing entropy on HEAs' phase composition remains debatable [2], while the initially undesirable intermetallics are found to be often useful in terms of mechanical properties [4].

The strength of many HEAs can be enhanced without a noticeable reduction in ductility through controllable precipitation of second-phase particles [5-9]. In this regard, eutectic HEAs (EHEAs) emerged as a promising way to achieve balanced properties [10-12]. EHEAs can be considered as natural, self-organized in situ composites due to a fine lamellar/rod-like structure formed already in the as-cast state. Such a structure takes advantage of each phase, for instance, the high ductility of an fcc phase and the strength of a B2 phase [13,14]. Many efforts have been devoted to designing, microstructure, and mechanical properties investigations of EHEAs based on 3d transition metals [14-26]. These alloys generally have fcc or $\mathrm{L}_{2}$ phase as a "soft" phase and $\mathrm{B} 2$, $\mu$, Laves, or other intermetallic phases as a "hard" reinforcement. In addition, thermomechanical processing was found to be a prospective method to enable a better strength-ductility combination in EHEAs [2729].

Meanwhile, a similar microstructure constitution is rarely found in HEAs based on refractory elements (RHEAs). RHEAs, predominantly composed of bcc solid solutions with the probable presence of secondary phases, are known for their high compressive strength at elevated temperatures but mostly have limited room-temperature ductility. RHEAs are appraised as promising materials for future gas turbine engines $[30,31]$. Implementing the EHEA philosophy seems to be an attractive option to improve the RHEAs' performance in many ways. The eutectic microstructure can enhance creep resistance or even ductility if a proper combination of phases with the required properties is found. Also, the good castability of eutectic alloys should eliminate the elemental segregations and hasten the real industrial application of RHEAs.

Recently, Wei et al. [32] explored the possibility of eutectic composites obtaining in a MoNbRe ${ }_{0.5} \mathrm{TaW}(\mathrm{TiC})_{\mathrm{x}}$ RHEA system. It was found that a $\mathrm{MoNbRe}_{0.5} \mathrm{TaW}(\mathrm{TiC})_{1.0}$ alloy with a eutectic structure consisted of a bcc solid solution and an fcc multicomponent carbide had high compressive yield strength $(1496 \pm 17 \mathrm{MPa})$ and peak strength $(1943 \pm 13 \mathrm{MPa})$ with reasonable plasticity at ambient temperature. The alloy was sup-

\footnotetext{
* Corresponding author.

E-mail address: yurchenko_nikita@bsu.edu.ru (N. Yurchenko).
} 
posed to benefit from the synergistic effect of second-phase and interphase strengthening. In turn, Zhu et al. [33] showed that $\mathrm{Al}$ promotes different types of eutectic microstructures composed of bcc and Laves phases in lightweight $\mathrm{Al}_{\mathrm{x}} \mathrm{CrNbTiZr}$ alloys. With an increase in $\mathrm{Al}$ content, the structure evolved from hypoeutectic to eutectic and hypereutectic. Unexpectedly, the room-temperature mechanical properties, namely compressive strength and fracture strain, of the eutectic $\mathrm{Al}_{0.75} \mathrm{CrNbTiZr}$ alloy were inferior to the rest of the alloys.

Unfortunately, many issues related to the eutectic RHEAs' (ERHEAs') development remain insufficiently studied. For example, there is no established strategy for the robust identification of such alloys. Several empirical methods have been proposed and efficiently applied for the EHEAs based on 3d transition metals, namely the mixing enthalpy [34], simple mixture [35], and pseudo-binary [36] methods. A CALPHAD (CALculation of PHAse Diagrams) approach has also been successfully used to identify EHEAs $[21,25,37]$. The CALPHAD allows obtaining a qualitative understanding of the alloys' phase formation compared to the empirical methods listed above. Moreover, the CALPHAD is widely considered as a pivotal instrument to accelerate the development of (R)HEAs, in particular, for high-temperature applications [38-42].

Additionally, many questions arise about the structure-property relationships in multiphase RHEAs. For instance, the contribution of individual phases to mechanical properties and the effect of their morphology and fraction remain unclear. Also, the microstructure evolution during plastic straining and associated deformation mechanisms were never studied in detail. Therefore, in the present work, three main aims were pursued: (i) to design a palette of RHEAs with different structures (eutectic, hypo-, and hypereutectic) using the CALPHAD method; (ii) to establish links between the structure and mechanical properties of the alloys, and (iii) to investigate the microstructure evolution and deformation mechanisms in a eutectic or near-eutectic RHEA(s).

\section{Alloy design}

A previous study [43] examined a lightweight $\mathrm{Al}_{20} \mathrm{Cr}_{10} \mathrm{Nb}_{15} \mathrm{Ti}_{20} \mathrm{~V}_{25} \mathrm{Zr}_{10}$ alloy with a composite-like hypoeutectic microstructure formed by a proeutectic B2 phase and a eutectic B2+C14 Laves phase mixture. This alloy was found to exhibit high strength at $800{ }^{\circ} \mathrm{C}$. Moreover, the Scheil model [43] correctly predicted the as-cast structure of this RHEA. Therefore, we attempted to find a fully eutectic $\mathrm{B} 2+\mathrm{C} 14$ Laves phase alloy in a simpler Al-Cr-Nb-Ti-Zr system by analyzing both equilibrium and non-equilibrium phase diagrams produced by the CALPHAD method.

The design strategy included several steps. Firstly, we searched for a single-phase bcc alloy with presumably high room-temperature ductility that would serve as a basis for further alloy development. Among possible equiatomic or near-equiatomic compositions in the Al-Cr-NbTi-Zr system, the NbTiZr ternaries appeared to be the most promising option according to the literature data [41,44,45]. Both the equilibrium phase diagram and the non-equilibrium Scheil solidification path (Fig. 1a, b) (produced by a Thermo-Calc (version 2020a) software and a TCHEA3 (high-entropy alloys) database) suggested a single bcc phase in a $\mathrm{Nb}_{30} \mathrm{Ti}_{40} \mathrm{Zr}_{30}$ (at.\%) alloy. This composition was chosen as a starting point for producing a eutectic alloy with the $\mathrm{B} 2+\mathrm{C} 14$ Laves phase structure by subsequent doping.

The second step was associated with obtaining an alloy with a dualphase bcc+Laves phase structure. It is known that $\mathrm{Cr}$ is one of the strongest Laves phase-forming elements in the Al-Cr-Nb-Ti-(V)-Zr system [41,46-49]; therefore, a $\mathrm{Cr}_{\mathrm{x}} \mathrm{Nb}_{30} \mathrm{Ti}_{40} \mathrm{Zr}_{30-\mathrm{x}}$ quasi-binary phase diagram was constructed (Fig. 1c). According to the diagram, an addition of $\mathrm{Cr}$ should result in the appearance of a C15 (fcc) Laves phase enriched with $\mathrm{Cr}$ and $\mathrm{Zr}$. The solvus temperature of the Laves phase increased with the $\mathrm{Cr}$ content. At $\sim 15$ at.\% of $\mathrm{Cr}$, the C15 Laves phase solvus became equal to the alloy's solidus temperature. We chose a $\mathrm{Cr}_{20} \mathrm{Nb}_{30} \mathrm{Ti}_{40} \mathrm{Zr}_{10}$ alloy with a presumably dual-phase as-cast structure composed of the bcc and C15 Laves phases. The Scheil solidification path (Fig. 1d) predicted that the $\mathrm{Cr}_{20} \mathrm{Nb}_{30} \mathrm{Ti}_{40} \mathrm{Zr}_{10}$ alloy should have a hypoeutectic structure with the proeutectic bcc phase.

At the third step, we added $\mathrm{Al}$ to the quaternary Cr-Nb-Ti-Zr alloy. Many studies have revealed that $\mathrm{Al}$ effectively decreases density and simultaneously increases strength and oxidation resistance of RHEAs [50-54]. In terms of the phase composition, the Al addition may (i) transform the bcc phase into the ordered B2 phase and (ii) change the polytype of the Laves phase from C15 (fcc) to C14 (hcp) [52,55-58]. Also, Al can promote the eutectic reaction in the Al-Cr-Nb-Ti-Zr system [33]. Therefore, an $\mathrm{Al}_{\mathrm{x}} \mathrm{Cr}_{20} \mathrm{Nb}_{30-\mathrm{x}} \mathrm{Ti}_{40} \mathrm{Zr}_{10}$ quasi-binary phase diagram was constructed (Fig. 1e). The diagram showed that a systematic substitution of $\mathrm{Nb}$ with $\mathrm{Al}$ led to an appearance of the C14 Laves phase enriched with $\mathrm{Al}, \mathrm{Cr}$, and $\mathrm{Zr}$. The Laves phase's solvus temperature rose with the $\mathrm{Al}$ addition and reached the maximum at $\sim 15$ at.\% of $\mathrm{Al}$. Also, a gradual increase in both liquidus and solidus temperatures was expected. However, no eutectic reaction could be observed; crystallization should start through a single bcc phase. Nevertheless, we chose an $\mathrm{Al}_{15} \mathrm{Cr}_{20} \mathrm{Nb}_{15} \mathrm{Ti}_{40} \mathrm{Zr}_{10}$ alloy with the highest temperature of the C14 Laves phase solvus and presumably hypoeutectic structure (according to the Scheil model (Fig. 1f)). Note that commercial CALPHAD databases cannot correctly predict the bcc-B2 transition in RHEAs [43,59-61], yet the available literature data suggest the possible $\mathrm{B} 2$ ordering in the $\mathrm{Al}_{15} \mathrm{Cr}_{20} \mathrm{Nb}_{15} \mathrm{Ti}_{40} \mathrm{Zr}_{10}$ alloy.

Finally, we have tried to find a eutectic-like reaction in the Al-Cr$\mathrm{Nb}-\mathrm{Ti}-\mathrm{Zr}$ system. It was revealed that a partial replacement of Ti with $\mathrm{Al}$ could be a suitable variant. For example, an $\mathrm{Al}_{15+\mathrm{x}} \mathrm{Cr}_{20} \mathrm{Nb}_{15} \mathrm{Ti}_{40-\mathrm{x}} \mathrm{Zr}_{10}$ quasi-binary phase diagram is shown in Fig. 2a. An increase in the $\mathrm{Al}$ (and decrease in $\mathrm{Ti}$ ) content should transform a hypoeutectic structure to eutectic and hypereutectic ones. According to the diagram, the eutectic point was located at $x \approx 13$ at.\% of $\mathrm{Al}$ and corresponded to an $\mathrm{Al}_{28} \mathrm{Cr}_{20} \mathrm{Nb}_{15} \mathrm{Ti}_{27} \mathrm{Zr}_{10}$ alloy. The Scheil solidification model (Fig. 2b) predicted almost concurrent crystallization of the bcc (B2) and $\mathrm{C} 14$ Laves phases in the $\mathrm{Al}_{28} \mathrm{Cr}_{20} \mathrm{Nb}_{15} \mathrm{Ti}_{27} \mathrm{Zr}_{10}$ alloy. Also, the $\mathrm{Al}_{23} \mathrm{Cr}_{20} \mathrm{Nb}_{15} \mathrm{Ti}_{32} \mathrm{Zr}_{10}$ and $\mathrm{Al}_{33} \mathrm{Cr}_{20} \mathrm{Nb}_{15} \mathrm{Ti}_{22} \mathrm{Zr}_{10}$ alloys with hypoand hypereutectic structures, respectively, were selected for experimental examination (Fig. 2a). Analysis of the Scheil solidification path suggested primary crystallization of the bcc (B2) phase in the $\mathrm{Al}_{23} \mathrm{Cr}_{20} \mathrm{Nb}_{15} \mathrm{Ti}_{32} \mathrm{Zr}_{10}$ alloy (Fig. 2c) and the C14 Laves phase in the $\mathrm{Al}_{33} \mathrm{Cr}_{20} \mathrm{Nb}_{15} \mathrm{Ti}_{22} \mathrm{Zr}_{10}$ alloy (Fig. 2d).

\section{Materials and methods}

The ingots of the alloys with nominal compositions of $\mathrm{Nb}_{30} \mathrm{Ti}_{40} \mathrm{Zr}_{30}$, $\mathrm{Cr}_{20} \mathrm{Nb}_{30} \mathrm{Ti}_{40} \mathrm{Zr}_{10}, \quad \mathrm{Al}_{15} \mathrm{Cr}_{20} \mathrm{Nb}_{15} \mathrm{Ti}_{40} \mathrm{Zr}_{10}, \quad \mathrm{Al}_{23} \mathrm{Cr}_{20} \mathrm{Nb}_{15} \mathrm{Ti}_{32} \mathrm{Zr}_{10}$, $\mathrm{Al}_{28} \mathrm{Cr}_{20} \mathrm{Nb}_{15} \mathrm{Ti}_{27} \mathrm{Zr}_{10}$, and $\mathrm{Al}_{33} \mathrm{Cr}_{20} \mathrm{Nb}_{15} \mathrm{Ti}_{22} \mathrm{Zr}_{10}$ (at.\%) were produced by vacuum arc melting of pure ( $\geq 99.9$ wt.\%) elements. The macrostructure of the produced ingots is presented in Supplementary information (Fig. S1). Specimens for microstructure observations and mechanical testing were cut from the central part of the ingots by an electric discharge machine.

The phase composition and microstructure of the alloys were studied for the as-cast state using X-ray diffraction (XRD), scanning electron microscopy (SEM), and transmission electron microscopy (TEM). Samples for XRD and SEM analysis were prepared by careful mechanical polishing. XRD analysis was performed using a RIGAKU diffractometer and $\mathrm{Cu} \mathrm{K} \alpha$ radiation with the wavelength of $1.5406 \AA$; a scanning rate and scanning interval were $3^{\circ} / \mathrm{min}$ and $20-100^{\circ}$, respectively. SEM investigations were carried out on an FEI Quanta 200 3D or a Nova NanoSEM 450 microscopes equipped with an energy-dispersive (EDS) detector. EBSD was conducted using an FEI Nova NanoSEM 450 FEG SEM equipped with a Hikari EBSD detector and a TSL OIM ${ }^{\mathrm{TM}}$ system version 6.0. This software was used to generate inverse pole figures (IPF) and phase maps. On the presented IPF map, the high angle boundaries (HABs) are indicated with black lines, while white lines denote the low angle boundaries (LABs). The bcc/B2 and C15/C14 Laves phases are shown in the presented phase maps with red and green colors, re- 


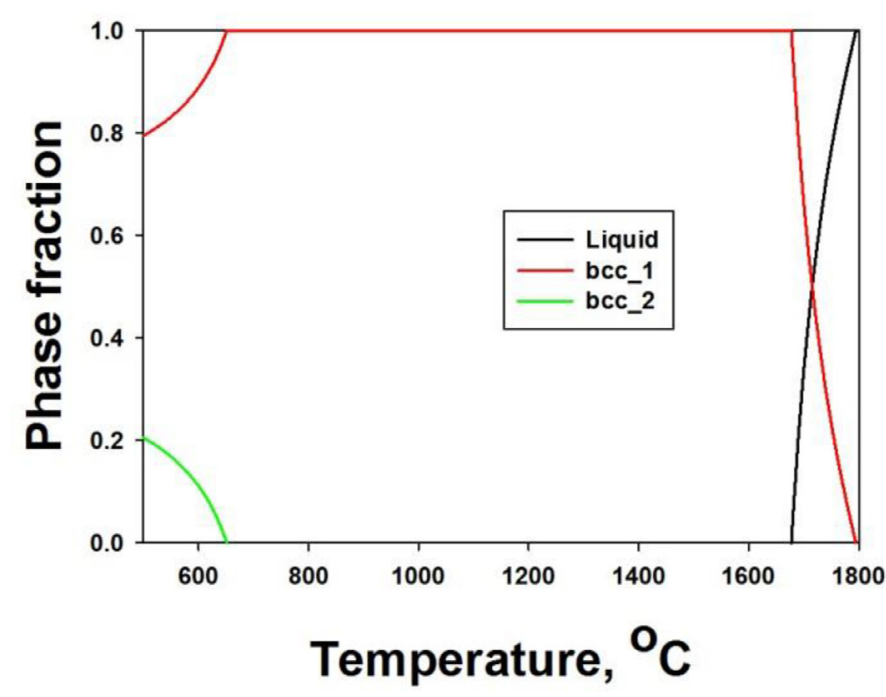

a

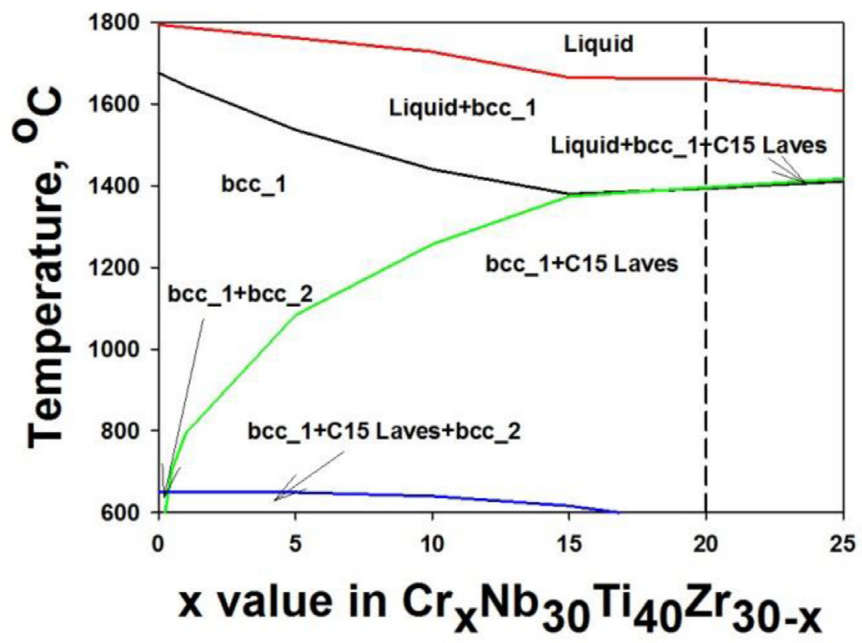

C

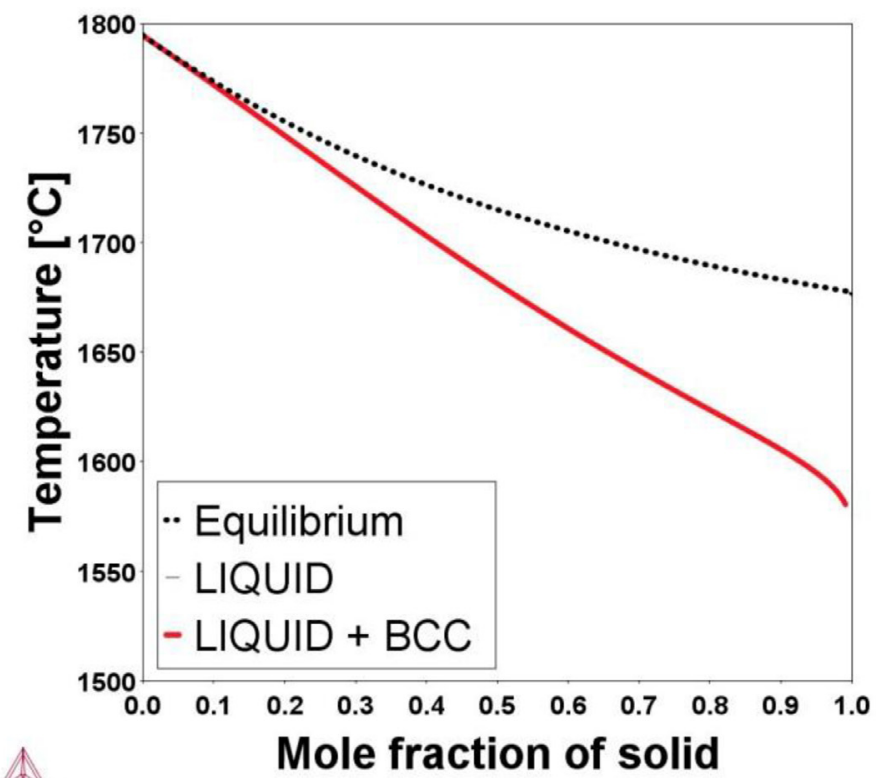

b

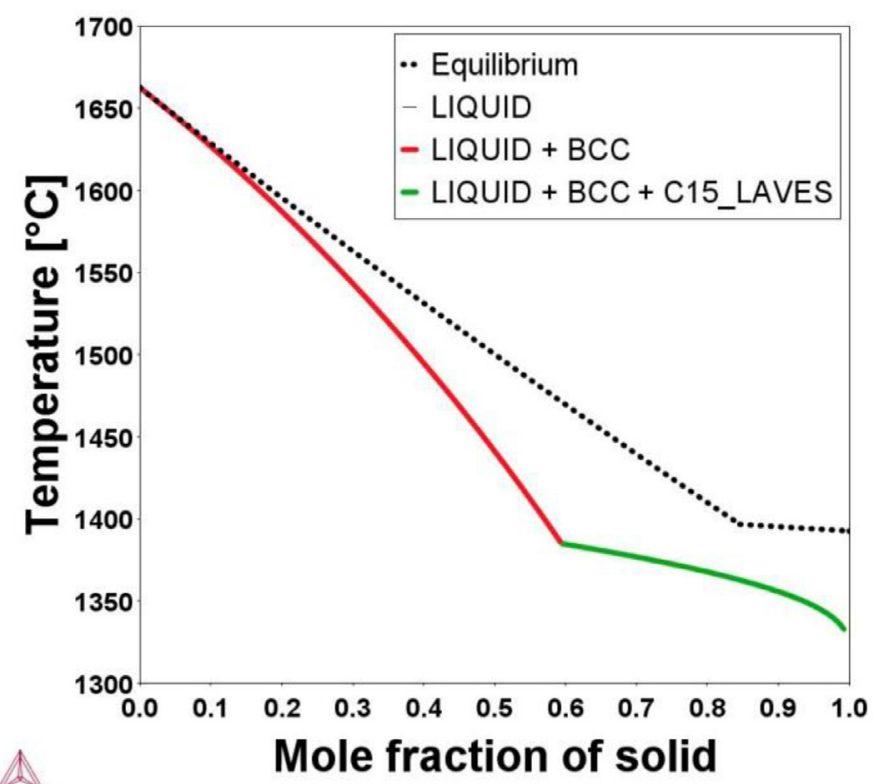

d

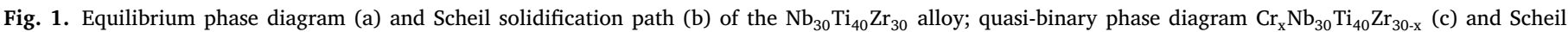

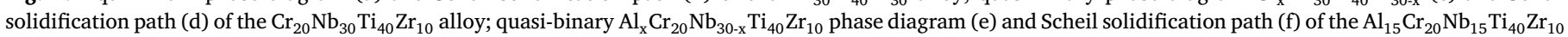
alloy.

spectively. All the EBSD maps are shown in the as-obtained conditions without any additional cleanup procedures. The volume fractions of different phases were measured by the areal analysis of SEM-BSE images and EBSD phase maps using a Digimizer Image Analysis Software. The difference between the fractions of the phases measured using SEM-BSE and EBSD data for the same alloys and conditions was $<2 \%$; data obtained by these two methods were averaged. Mechanically pre-thinned to $100 \mu \mathrm{m}$ foils were prepared for TEM analysis by conventional twin-jet electro-polishing at $-35{ }^{\circ} \mathrm{C}$ and an applied voltage of $29.5 \mathrm{~V}$ in a mixture of $600 \mathrm{ml}$ of methanol, $360 \mathrm{ml}$ of butanol, and $60 \mathrm{ml}$ of perchloric acid. TEM investigations were performed using a JEOL JEM-2100 microscope equipped with an EDS detector at an accelerating voltage of $200 \mathrm{kV}$.
The densities of the alloys were determined by the hydrostatic weighing method. The density of the ( $\mathrm{Cr}$ )-Nb-Ti-Zr alloys was measured to be $6.37-6.44 \mathrm{~g} / \mathrm{cm}^{3}$. The Al-containing alloys showed a significantly lower density of $5.23-5.55 \mathrm{~g} / \mathrm{cm}^{3}$. The detailed information can be found in Supplementary information (Fig. S2a).

Isothermal compression of rectangular samples measured $6 \times 4 \times 4 \mathrm{~mm}^{3}$ was carried out at $22,600,700,800$, or $1000{ }^{\circ} \mathrm{C}$ in the air using an Instron 300LX test machine equipped with a radial furnace. The samples tested at $600,700,800$, or $1000{ }^{\circ} \mathrm{C}$ were placed into the preheated furnace and held for $\approx 10 \mathrm{~min}$ to equilibrate the temperature before testing. The samples' temperature was controlled by a thermocouple attached to a side surface of the specimen. The 


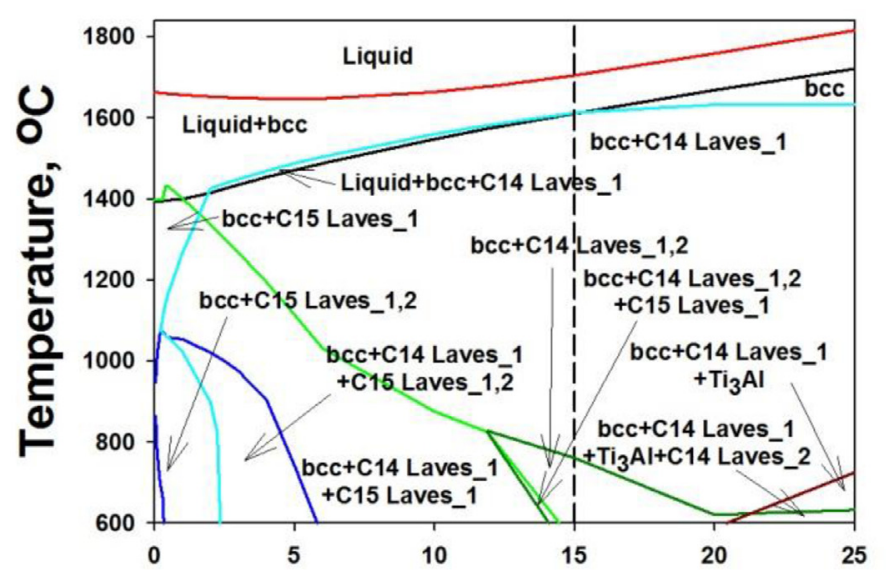

$x$ value in $\mathrm{Al}_{\mathbf{x}} \mathrm{Cr}_{20 \mathrm{Nb}} 30-\mathrm{Ti} 40 \mathrm{Zr} 10$

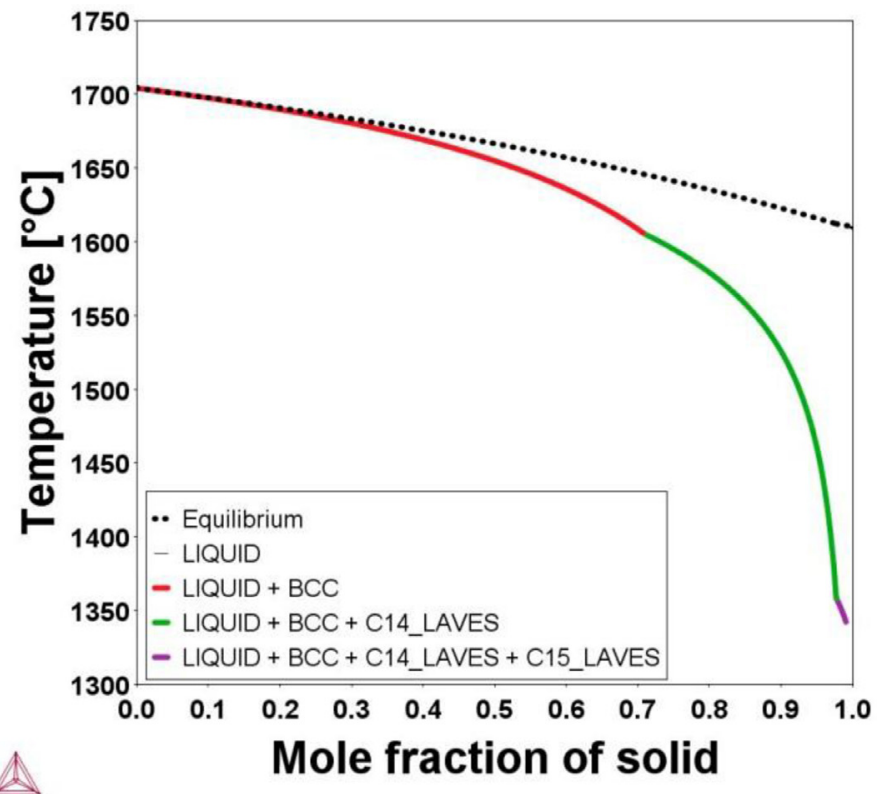

$f$

Fig. 1. Continued

initial strain rate was $10^{-4} \mathrm{~s}^{-1}$. Testing was carried out to the fracture of the specimens or to $50 \%$ of strain.

For the $\mathrm{Al}_{28} \mathrm{Cr}_{20} \mathrm{Nb}_{15} \mathrm{Ti}_{27} \mathrm{Zr}_{10}$ alloy, two additional compression tests at $800{ }^{\circ} \mathrm{C}$ were conducted. The alloy's samples were compressed to either $\varepsilon \approx 0.6$ or $11.2 \%$ of strain. To arrest the structure after compression, the samples were quenched in water immediately after the test termination. The compressed to $\varepsilon \approx 0.6,11.2$, or $50 \%$ samples of the $\mathrm{Al}_{28} \mathrm{Cr}_{20} \mathrm{Nb}_{15} \mathrm{Ti}_{27} \mathrm{Zr}_{10}$ alloy were cut in half, and their structures were studied on a plane parallel to the compression axis.

The $\mathrm{Nb}_{30} \mathrm{Ti}_{40} \mathrm{Zr}_{30}$ alloy was additionally tested under tension at room temperature. Specimens with the gauge dimensions of $6 \times 3 \times 1 \mathrm{~mm}^{3}$ were used for mechanical tests under tension at an initial strain rate of $10^{-4} \mathrm{~s}^{-1}$ to fracture. Elongation to fracture was determined by the measurements of spacing between marks designating the gauge length before and after the test.

The Vickers microhardness, HV, was measured on polished crosssection surfaces of the as-cast specimens using a $136^{\circ}$ Vickers diamond pyramid under a $300 \mathrm{~g}$ load applied for $15 \mathrm{~s}$. Each data point represented an average of at least ten individual measurements. The detailed information can be found in Supplementary information (Fig. S2b).

\section{Results}

\subsection{Microstructure and phase composition}

SEM-EBSD analysis showed that the single-phase bcc $\mathrm{Nb}_{30} \mathrm{Ti}_{40} \mathrm{Zr}_{30}$ alloy possessed a microstructure with coarse $(\sim 150 \mu \mathrm{m})$ polygonal grains without any visible chemical heterogeneity (Fig. 3a, b; Table 1). Some fine (few tens of microns) grains, mostly in the larger grains' triple junctions, were observed. The microstructure of the $\mathrm{Cr}_{20} \mathrm{Nb}_{30} \mathrm{Ti}_{40} \mathrm{Zr}_{10}$ alloy was presented by a primary bcc matrix and a eutectic mixture of the $\mathrm{C} 15$ Laves and bcc phases (Fig. 3c, d). The eutectic regions were predominantly located in the interdendritic areas (Fig. 3c). EDS analysis showed enrichment of the $\mathrm{C} 15$ Laves phase with $\mathrm{Cr}$ and $\mathrm{Zr}$, whilst the bcc phase was enriched with $\mathrm{Nb}$ (Table 1 ). The amount of the Laves phase was $13 \%$.

In turn, both the $\mathrm{Al}_{15} \mathrm{Cr}_{20} \mathrm{Nb}_{15} \mathrm{Ti}_{40} \mathrm{Zr}_{10}$ and $\mathrm{Al}_{23} \mathrm{Cr}_{20} \mathrm{Nb}_{15} \mathrm{Ti}_{32} \mathrm{Zr}_{10}$ alloys exhibited typical hypoeutectic microstructures with a proeutectic
Table 1

Chemical compositions of structural constituents of the Al-Cr-Nb-Ti-Zr alloys.

\begin{tabular}{|c|c|c|c|c|c|c|}
\hline Element, at.\% & $\mathrm{Al}$ & $\mathrm{Cr}$ & $\mathrm{Nb}$ & $\mathrm{Ti}$ & $\mathrm{Zr}$ & $\begin{array}{l}\text { Volume } \\
\text { fraction, } \%\end{array}$ \\
\hline \multicolumn{7}{|l|}{$\mathrm{Nb}_{30} \mathrm{Ti}_{40} \mathrm{Zr}_{30}$} \\
\hline Grains & - & - & 30.1 & 40.0 & 29.9 & - \\
\hline $\begin{array}{l}\text { Alloy } \\
\text { composition }\end{array}$ & - & - & 30.0 & 40.1 & 29.9 & - \\
\hline $\begin{array}{l}\mathrm{Cr}_{20} \mathrm{Nb}_{30} \mathrm{Ti}_{40} \mathrm{Z} \\
\text { bcc phase }\end{array}$ & - & 17.0 & 33.2 & 40.4 & 9.4 & 87 \\
\hline $\begin{array}{l}\text { C15 Laves } \\
\text { phase }\end{array}$ & - & 41.9 & 14.3 & 26.7 & 17.1 & 13 \\
\hline $\begin{array}{l}\text { Alloy } \\
\text { composition }\end{array}$ & - & 20.7 & 27.4 & 40.3 & 11.6 & - \\
\hline \multicolumn{7}{|c|}{$\mathrm{Al}_{15} \mathrm{Cr}_{20} \mathrm{Nb}_{15} \mathrm{Ti}_{40} \mathrm{Zr}_{10}$} \\
\hline B2 phase & 14.0 & 16.0 & 17.7 & 44.9 & 7.4 & 69 \\
\hline $\begin{array}{l}\text { C14 Laves } \\
\text { phase }\end{array}$ & 15.6 & 27.1 & 10.4 & 30.8 & 16.1 & 31 \\
\hline $\begin{array}{l}\text { Alloy } \\
\text { composition }\end{array}$ & 14.8 & 20.2 & 15.1 & 39.6 & 10.3 & - \\
\hline \multicolumn{7}{|c|}{$\mathrm{Al}_{23} \mathrm{Cr}_{20} \mathrm{Nb}_{15} \mathrm{Ti}_{32} \mathrm{Zr}_{10}$} \\
\hline B2 phase & 20.1 & 15.2 & 18.6 & 39.9 & 6.2 & 52 \\
\hline $\begin{array}{l}\text { C14 Laves } \\
\text { phase }\end{array}$ & 23.7 & 28.2 & 9.7 & 20.8 & 17.6 & 48 \\
\hline $\begin{array}{l}\text { Alloy } \\
\text { composition }\end{array}$ & 21.6 & 20.8 & 15.2 & 32.3 & 10.1 & - \\
\hline \multicolumn{7}{|c|}{$\mathrm{Al}_{28} \mathrm{Cr}_{20} \mathrm{Nb}_{15} \mathrm{Ti}_{27} \mathrm{Zr}_{10}$} \\
\hline B2 phase & 25.4 & 14.6 & 16.2 & 36.8 & 7.0 & 43 \\
\hline $\begin{array}{l}\text { C14 Laves } \\
\text { phase }\end{array}$ & 31.8 & 31.3 & 9.4 & 13.1 & 14.4 & 57 \\
\hline $\begin{array}{l}\text { Alloy } \\
\text { composition }\end{array}$ & 26.6 & 20.5 & 15.3 & 27.4 & 10.2 & - \\
\hline \multicolumn{7}{|c|}{$\mathrm{Al}_{33} \mathrm{Cr}_{20} \mathrm{Nb}_{15} \mathrm{Ti}_{22} \mathrm{Zr}_{10}$} \\
\hline B2 phase & 29.2 & 14.4 & 17.1 & 33.5 & 5.8 & 34 \\
\hline $\begin{array}{l}\text { C14 Laves } \\
\text { phase }\end{array}$ & 32.1 & 28.0 & 13.9 & 12.5 & 13.5 & 66 \\
\hline $\begin{array}{l}\text { Alloy } \\
\text { composition }\end{array}$ & 30.8 & 20.9 & 15.4 & 22.7 & 10.2 & - \\
\hline
\end{tabular}

B2 phase and a eutectic mixture of C14 Laves and B2 phases (Fig. 4a-d). The B2 ordering was revealed by XRD analysis (see Fig. S3 and Table S1 in Supplementary information). An almost continuous Laves phase layer separated the eutectic regions with a lamellar structure and the 


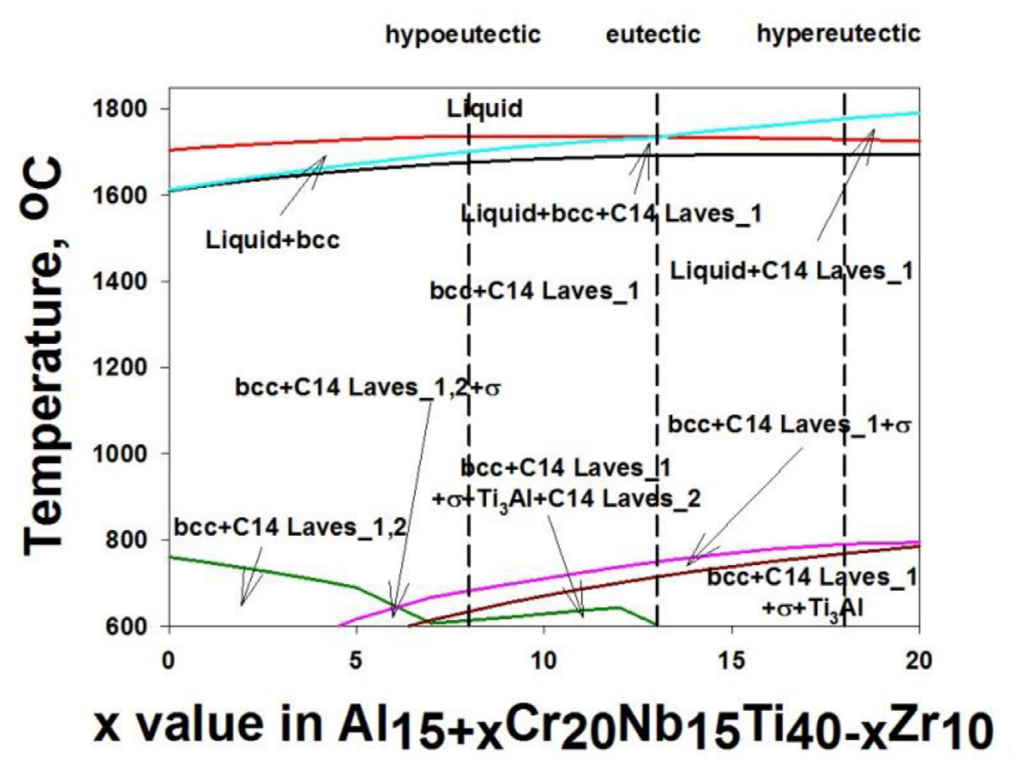

a

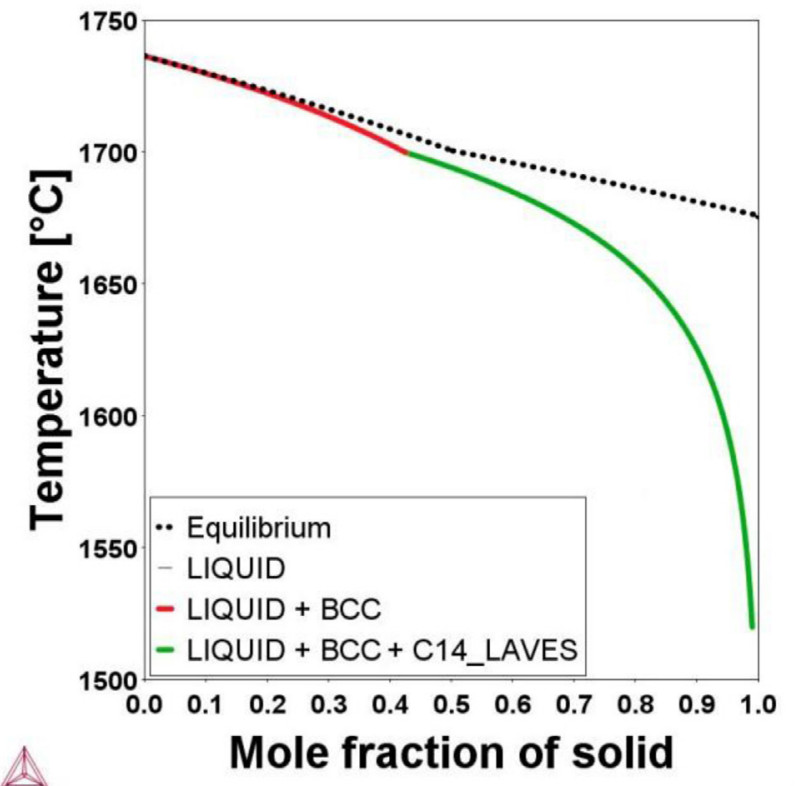

c

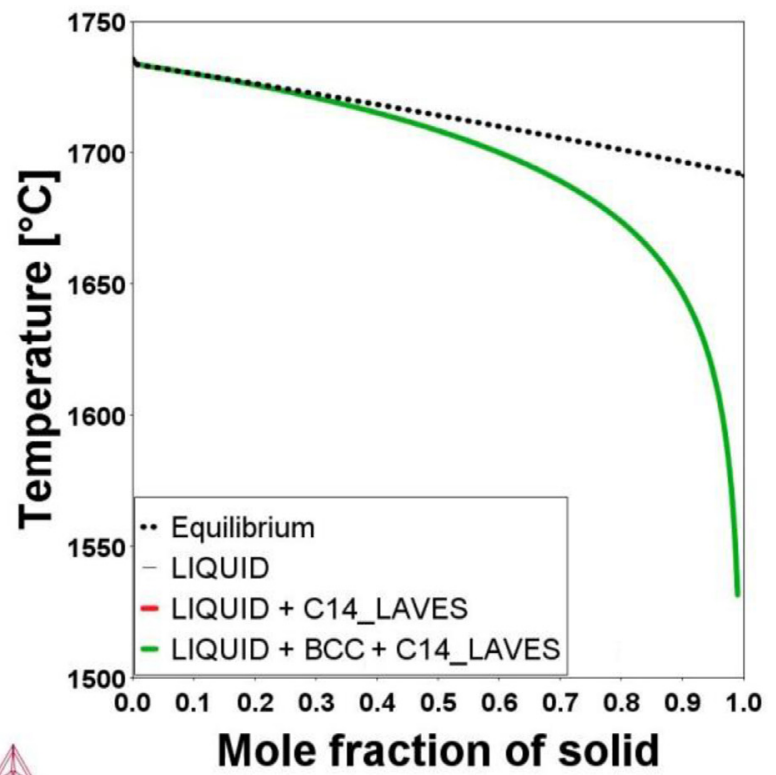

$\mathrm{b}$

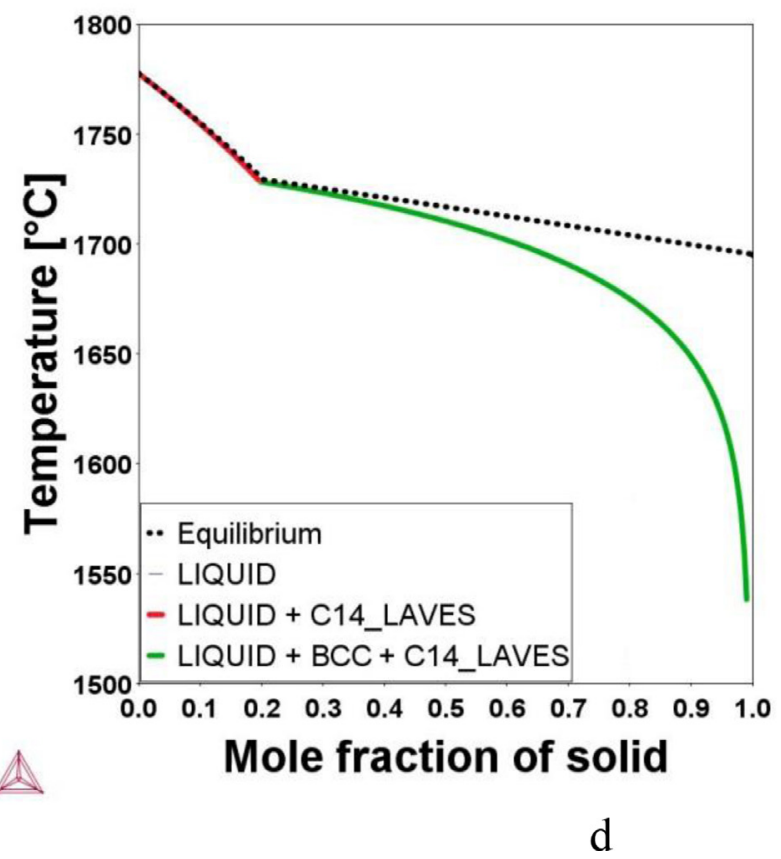

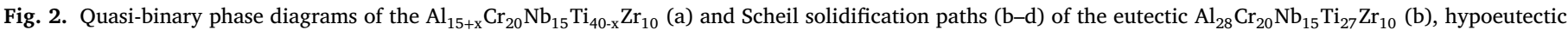
$\mathrm{Al}_{23} \mathrm{Cr}_{20} \mathrm{Nb}_{15} \mathrm{Ti}_{32} \mathrm{Zr}_{10}$ (c), and hypereutectic $\mathrm{Al}_{33} \mathrm{Cr}_{20} \mathrm{Nb}_{15} \mathrm{Ti}_{22} \mathrm{Zr}_{10}$ (d) alloys.

proeutectic B2 phase. The Laves phase was enriched with $\mathrm{Cr}$ and $\mathrm{Zr}$, while the $\mathrm{B} 2$ phase was enriched with $\mathrm{Nb}$ and $\mathrm{Ti}$ (Table 1 ). The concentrations of $\mathrm{Al}$ in both phases were very close. The volume fractions of the Laves phase were $31 \%$ and $48 \%$ in the $\mathrm{Al}_{15} \mathrm{Cr}_{20} \mathrm{Nb}_{15} \mathrm{Ti}_{40} \mathrm{Zr}_{10}$ and $\mathrm{Al}_{23} \mathrm{Cr}_{20} \mathrm{Nb}_{15} \mathrm{Ti}_{32} \mathrm{Zr}_{10}$ alloys, respectively. In the $\mathrm{Al}_{23} \mathrm{Cr}_{20} \mathrm{Nb}_{15} \mathrm{Ti}_{32} \mathrm{Zr}_{10}$ alloy, some globular B2/C14 Laves phase particles were also observed inside the eutectic regions (Fig. 4c, d).

The $\mathrm{Al}_{28} \mathrm{Cr}_{20} \mathrm{Nb}_{15} \mathrm{Ti}_{27} \mathrm{Zr}_{10}$ alloy had a typical eutectic microstructure (Fig. 5a, b) consisting of the $\mathrm{B} 2$ matrix with lamellar precipitations of the $\mathrm{C} 14$ Laves phase (due to which the B2 phase often had a lamellar-like morphology as well). The C14 Laves phase volume fraction was $57 \%$ (Table 1). On the boundaries of the eutectic cells, some spherical B2/C14 Laves phase particles were observed. The elemental distributions between the constitutive phases were similar to those in the previous alloys, except for the slight partitioning of $\mathrm{Al}$ to the Laves phase.

For a more in-depth study of the eutectic $\mathrm{Al}_{28} \mathrm{Cr}_{20} \mathrm{Nb}_{15} \mathrm{Ti}_{27} \mathrm{Zr}_{10}$ alloy, TEM was used (Fig. 5c). TEM examination confirmed the B2/C14 Laves phase eutectic structure with an average interlamellar spacing of $\sim 200 \mathrm{~nm}$. The following orientation relationship (OR) between the B2 and C14 Laves phases was determined: $(011)_{\mathrm{B} 2}||(10 \overline{1} 3)_{\mathrm{C} 14}$ and $[1 \overline{1} 1]_{\mathrm{B} 2}||[3 \overline{3} 0 \overline{1}]_{\mathrm{C} 14}$

To the authors' best knowledge, such OR has never been reported up to date. Meantime, any typical ORs between the bcc and hcp phases, 


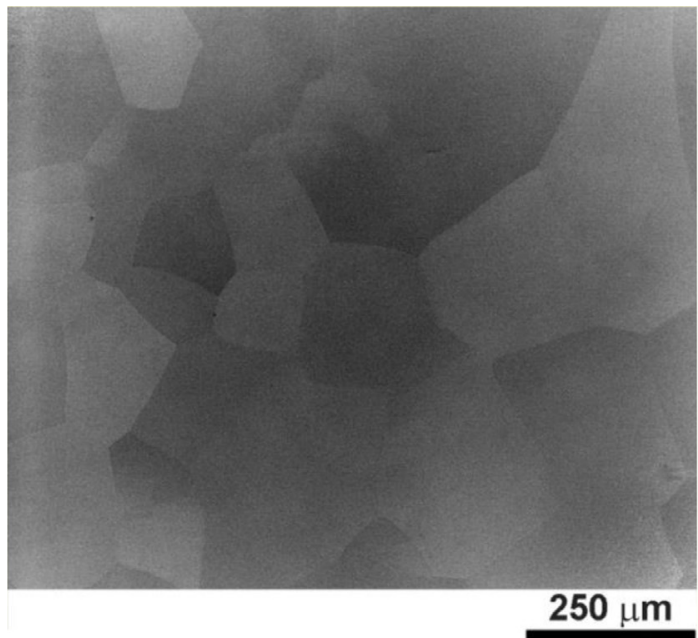

a

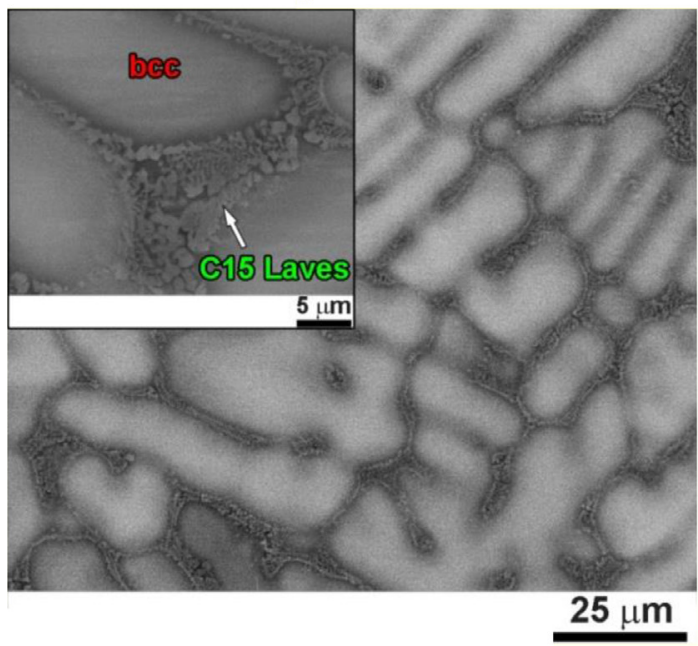

c

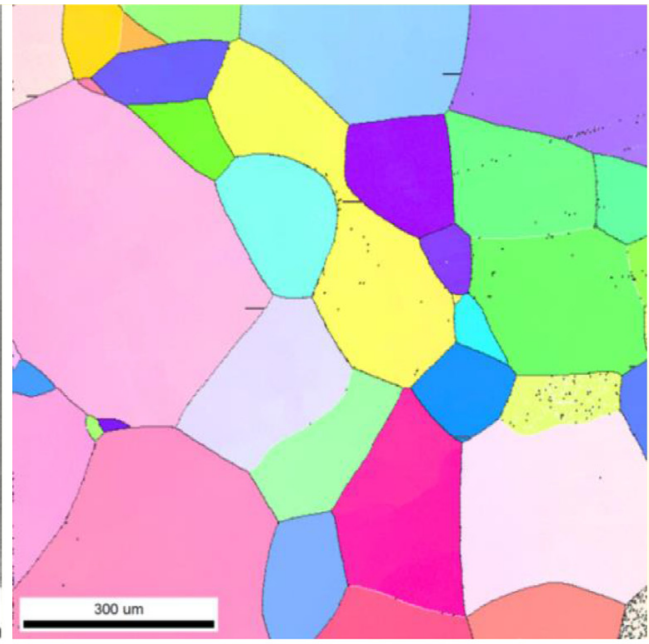

b

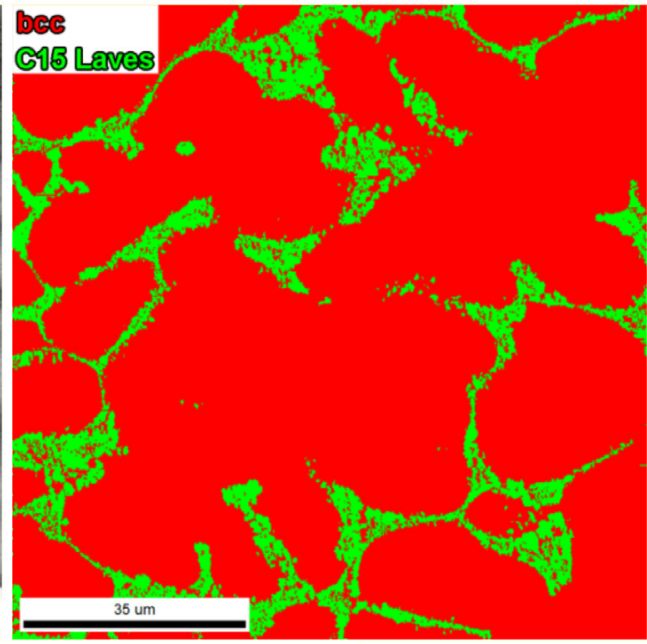

d

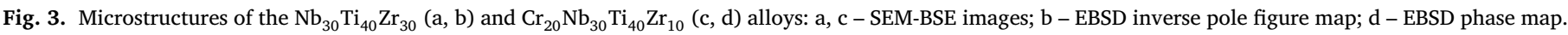

like Burgers, Potter, or Pitsch-Schrader [62], were absent in the eutectic alloy.

Finally, the $\mathrm{Al}_{33} \mathrm{Cr}_{20} \mathrm{Nb}_{15} \mathrm{Ti}_{22} \mathrm{Zr}_{10}$ alloy possessed a hypereutectic microstructure with the proeutectic $\mathrm{C} 14$ Laves phase domains embedded into the eutectic C14 Laves+B2 phase matrix (Fig. 5d, e). The amount of the Laves phase in the alloy was $66 \%$. The B2 phase was enriched with $\mathrm{Nb}$ and $\mathrm{Ti}$, while the $\mathrm{C} 14$ Laves phase - with $\mathrm{Cr}$ and $\mathrm{Zr}$; $\mathrm{Al}$ was distributed between the phases almost equally.

\subsection{Mechanical properties}

To establish temperature dependencies of the alloys' strength and ductility, we used compression tests at $22-1000{ }^{\circ} \mathrm{C}$ (Fig. 6). Mechanical properties obtained during compression were summarized in Table 2.

At $22{ }^{\circ} \mathrm{C}$, the $\mathrm{Nb}_{30} \mathrm{Ti}_{40} \mathrm{Zr}_{30}$ alloy exhibited a combination of modest yield strength (675 MPa), excellent compressive ductility ( $>50 \%$ ), and pronounced strain hardening capacity (Fig. 6a; Table 2). The $\mathrm{Cr}_{20} \mathrm{Nb}_{30} \mathrm{Ti}_{40} \mathrm{Zr}_{10}$ alloy demonstrated higher strength (1005 MPa) and strain hardening capacity but much lower compressive ductility (10.9\%). The $\mathrm{Al}_{15} \mathrm{Cr}_{20} \mathrm{Nb}_{15} \mathrm{Ti}_{40} \mathrm{Zr}_{10}$ alloy was the strongest ( $>1700 \mathrm{MPa}$ ) among the alloys. Also, the $\mathrm{Al}_{15} \mathrm{Cr}_{20} \mathrm{Nb}_{15} \mathrm{Ti}_{40} \mathrm{Zr}_{10}$ alloy was the only alloy among the Al-containing counterparts, which showed some room-temperature compressive ductility $(\sim 4 \%)$.
Meanwhile, the $\mathrm{Al}_{23} \mathrm{Cr}_{20} \mathrm{Nb}_{15} \mathrm{Ti}_{32} \mathrm{Zr}_{10}, \mathrm{Al}_{28} \mathrm{Cr}_{20} \mathrm{Nb}_{15} \mathrm{Ti}_{27} \mathrm{Zr}_{10}$, and $\mathrm{Al}_{33} \mathrm{Cr}_{20} \mathrm{Nb}_{15} \mathrm{Ti}_{22} \mathrm{Zr}_{10}$ alloys were fractured in the elastic region.

The temperature rising to $600-1000{ }^{\circ} \mathrm{C}$ resulted in a gradual decrease in strength and increased compressive ductility (Fig. 6b-e; Table 2). However, the Al content's enlargement shifted the ductilization temperature to higher values. Specifically, the $\mathrm{Al}_{23} \mathrm{Cr}_{20} \mathrm{Nb}_{15} \mathrm{Ti}_{32} \mathrm{Zr}_{10}$ alloy became ductile at only $700{ }^{\circ} \mathrm{C}$, the $\mathrm{Al}_{28} \mathrm{Cr}_{20} \mathrm{Nb}_{15} \mathrm{Ti}_{27} \mathrm{Zr}_{10}$ alloy at $800{ }^{\circ} \mathrm{C}$, and the $\mathrm{Al}_{33} \mathrm{Cr}_{20} \mathrm{Nb}_{15} \mathrm{Ti}_{22} \mathrm{Zr}_{10}$ alloy - at $1000{ }^{\circ} \mathrm{C}$. Correspondingly, a higher $\mathrm{Al}$ content led to enhanced strength at elevated temperature, except for $T=1000{ }^{\circ} \mathrm{C}$, when the $\mathrm{Nb}_{30} \mathrm{Ti}_{40} \mathrm{Zr}_{30}$ became stronger than the $\mathrm{Cr}_{20} \mathrm{Nb}_{30} \mathrm{Ti}_{40} \mathrm{Zr}_{10}, \mathrm{Al}_{15} \mathrm{Cr}_{20} \mathrm{Nb}_{15} \mathrm{Ti}_{40} \mathrm{Zr}_{10}$, and even $\mathrm{Al}_{23} \mathrm{Cr}_{20} \mathrm{Nb}_{15} \mathrm{Ti}_{32} \mathrm{Zr}_{10}$ alloys. Some modifications in the alloys' mechanical behavior with the temperature increase should also be noted. Almost all alloys demonstrated a curve with short strengthening and softening stages, followed by a prolonged nearly steady-state flow stage.

\subsection{Microstructure after compression}

To gain more insights into the mechanical behavior of the eutectic $\mathrm{Al}_{28} \mathrm{Cr}_{20} \mathrm{Nb}_{15} \mathrm{Ti}_{27} \mathrm{Zr}_{10}$ alloy, we examined its microstructure after different strains at $800{ }^{\circ} \mathrm{C}$ (Fig. 7a). According to SEM analysis, both after compression to $\varepsilon \approx 0.6$ and $11.2 \%$ of height reduction (which corresponded to the strain hardening or softening stages, respectively, in Fig. 7a), no visible changes in the alloy's structure were detected 


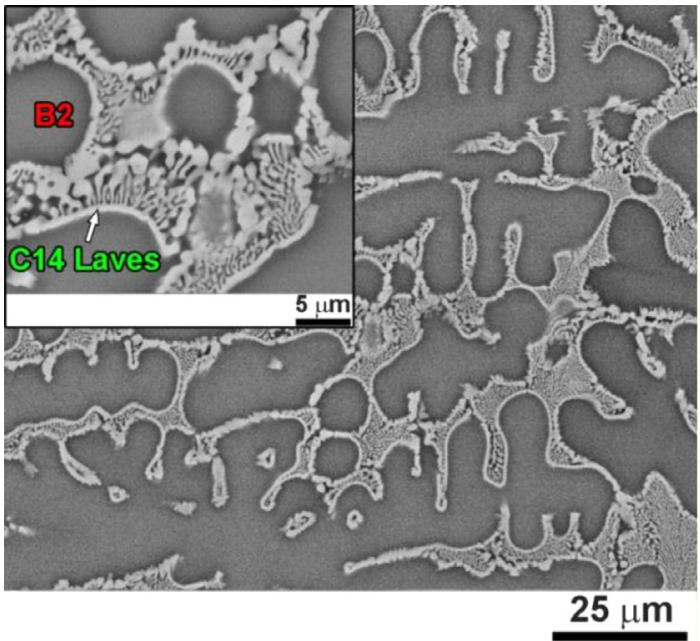

a

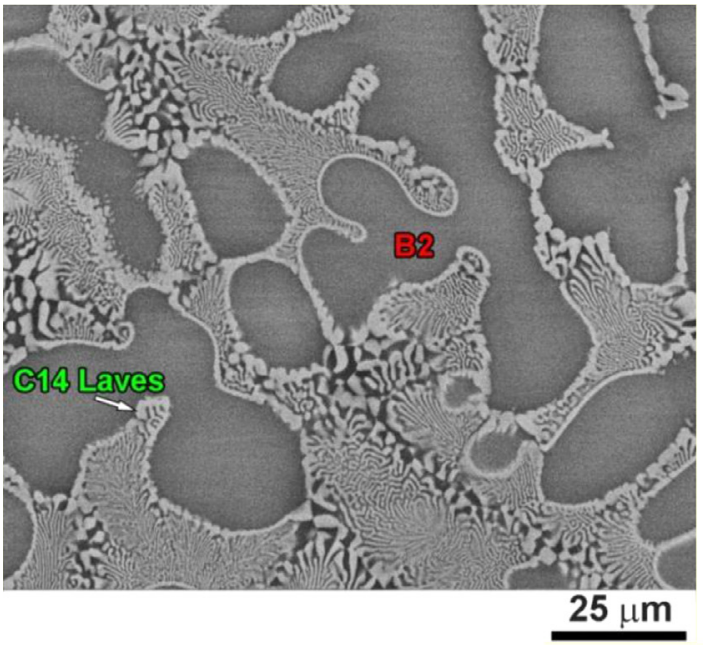

C

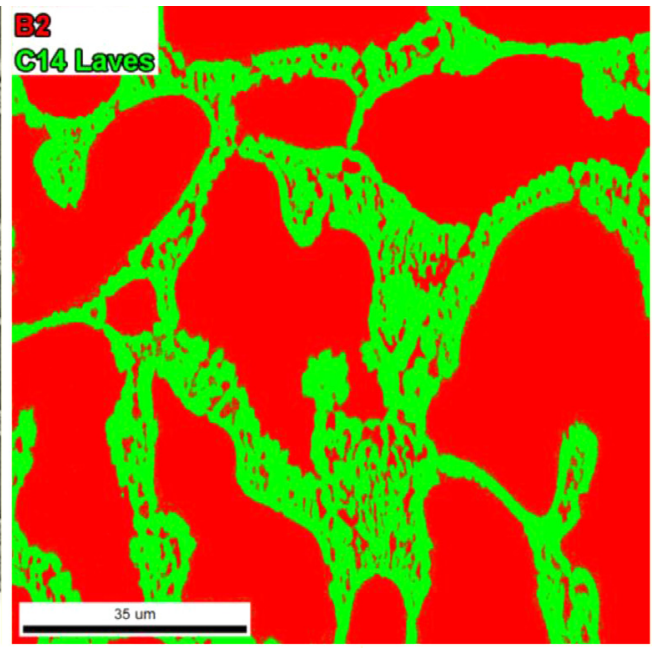

b

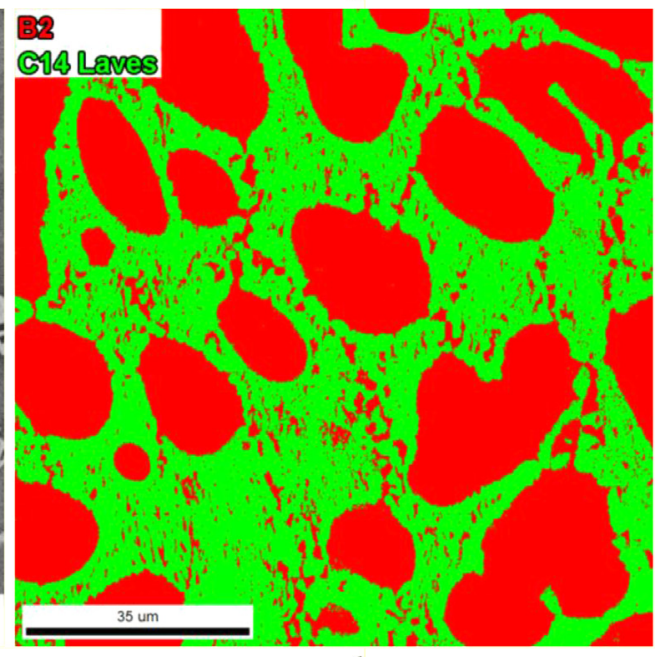

d

Fig. 4. Microstructures of the $\mathrm{Al}_{15} \mathrm{Cr}_{20} \mathrm{Nb}_{15} \mathrm{Ti}_{40} \mathrm{Zr}_{10}$ (a, b) and $\mathrm{Al}_{23} \mathrm{Cr}_{20} \mathrm{Nb}_{15} \mathrm{Ti}_{32} \mathrm{Zr}_{10}$ (c, d): a, c-SEM-BSE images; b, d - EBSD phase maps.

(Fig. 7 b, c). The alloy retained the lamellar morphology (the B2 matrix sliced by the $\mathrm{C} 14$ Laves phase lamellae) even after $\varepsilon \approx 50 \%$; however, the lamellae were often bent and/or reoriented along the metal flow direction (Fig. 7d). No evident signs of dynamic recrystallization or glodularization were found. However, profuse precipitation of tiny particles inside the B2 matrix should be noted.

TEM bright-field image of the specimen compressed to $\varepsilon \approx 0.6 \%$ revealed individual dislocations within the B2 phase, while no signs of deformation activity were observed inside the Laves phase (Fig. 8a). The characteristic fringe contrast was seen in the B2/C14 interphases suggesting a good match between the phases. Also, the formation of an ordered hcp $\left(\mathrm{D0}_{19}\right)$ phase particles (visible as dark and white particles in Fig. 8a and $\mathbf{b}$, respectively) was detected. The $\mathrm{D}_{19}$ particles had an irregular shape and precipitated inside the $\mathrm{B} 2$ phase adjacent to the $\mathrm{B} 2 / \mathrm{C} 14$ interfaces preferentially. According to EDS analysis, the $\mathrm{D}_{19}$ particles were enriched with $\mathrm{Ti}$ and $\mathrm{Nb}$ but depleted of $\mathrm{Cr}$ and $\mathrm{Zr}$; their chemical composition could be expressed as $\mathrm{Al}_{28} \mathrm{Cr}_{5} \mathrm{Nb}_{18} \mathrm{Ti}_{45} \mathrm{Zr}_{4}$. The volume fraction of the $\mathrm{D}_{19}$ phase was estimated to be $\sim 3 \%$.

Both the B2 and C14 Laves phases were involved in plastic deformation after compression to a higher strain of $\varepsilon \approx 11.2 \%$ (Fig. 8c). The increased dislocation density was observed in the B2 phase lamellae; at the same time, high-density planar defects emerged in the C14 Laves phase. The volume fraction, shape, and chemical composition of the $\mathrm{D}_{19}$ particles were not noticeably changed due to the compression strain increment from $0.6 \%$ to $11.2 \%$ (Fig. $8 \mathrm{~d}$ ).

After $50 \%$ of height reduction (Fig. 8e), the intense substructure formation presented by dense dislocation walls and arrays was observed in the B2 phase. Nevertheless, the B2 phase retained its ordered state, as confirmed by the $\{100\}$ superlattice spots in a [001] zone axis in the selected area diffraction pattern (insert in Fig. 8e). Plastic deformation of the C14 Laves phase at this level of strain was accompanied by the appearance of multiple transversal microbands and the corresponding lamellae bending. For the bent areas, serrations on the B2/C14 interfaces should be noted. Meanwhile, the $\mathrm{D}_{19}$ phase evolved into relatively large needle-shaped intersecting particles (Fig. 8f). The $\mathrm{D}_{19}$ needles propagated across the $\mathrm{B} 2$ interlayers from one $\mathrm{B} 2 / \mathrm{C} 14$ interphase to another; however, these particles were not observed in the Laves phase. A triple OR between the $\mathrm{B} 2, \mathrm{C} 14$ Laves, and $\mathrm{D}_{19}$ phases was revealed, which could be expressed as $(011)_{\mathrm{B} 2} \|(10 \overline{1} 3)_{\mathrm{C} 14}||(0 \overline{2} 21)_{\mathrm{D} 019}$. The $\mathrm{D}_{19}$ needles were inclined $\sim 45^{\circ}$ from the interphase boundaries. The volume fraction of the $\mathrm{D}_{19}$ phase increased to $13 \%$ after a $50 \%$ height reduction. Besides, the chemical composition of the $\mathrm{D}_{19}$ particles slightly changed: they became richer with $\mathrm{Ti}$ and leaner in $\mathrm{Nb}, \mathrm{Cr}$, and $\mathrm{Zr}\left(\mathrm{Al}_{28} \mathrm{Cr}_{4} \mathrm{Nb}_{14} \mathrm{Ti}_{51} \mathrm{Zr}_{3}\right)$. Finally, no evidence of dynamic recrystallization in either of the phases was found. 


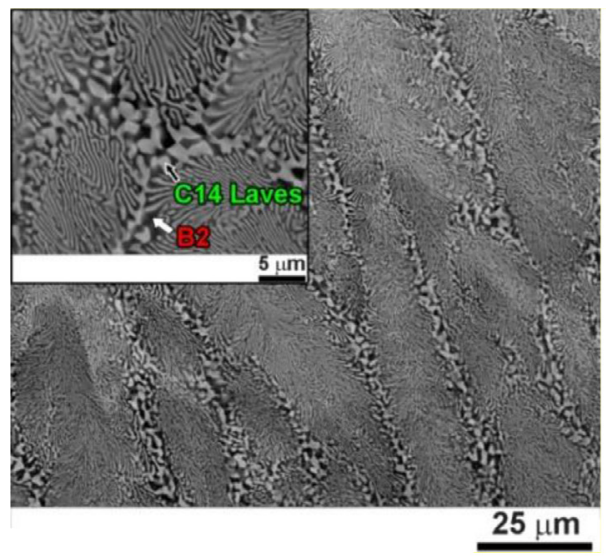

a

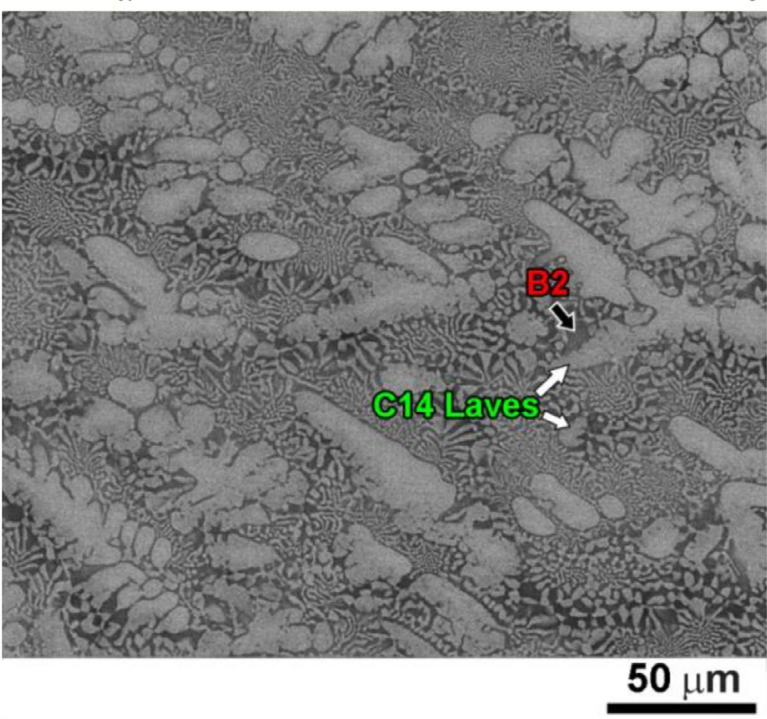

d

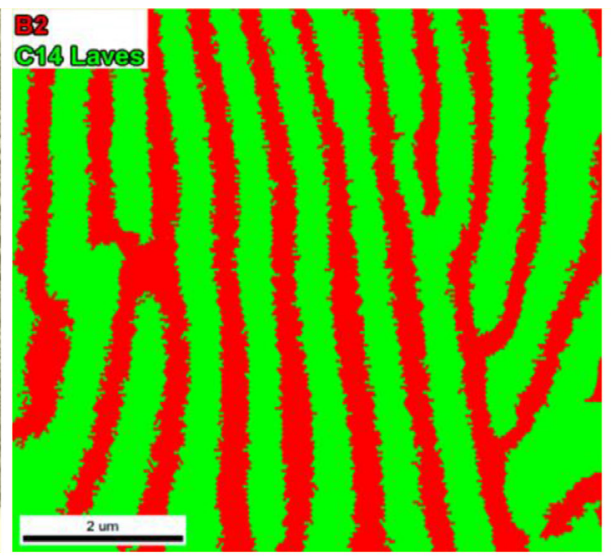

b

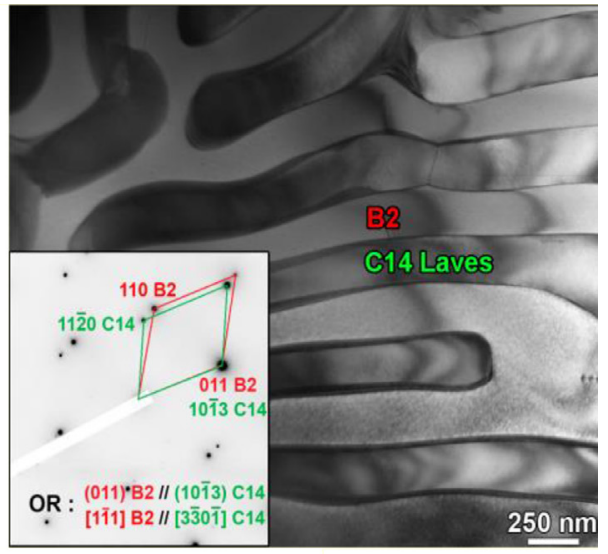

c

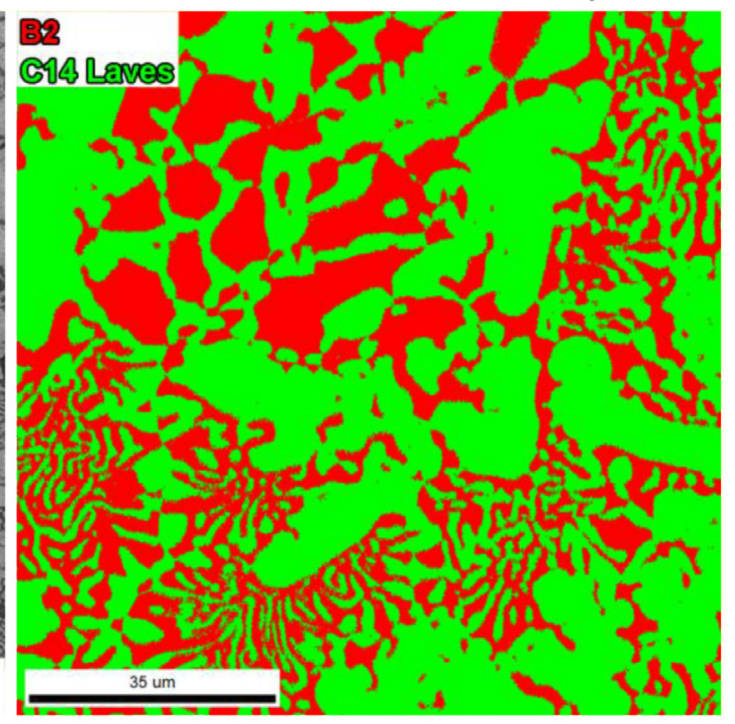

e

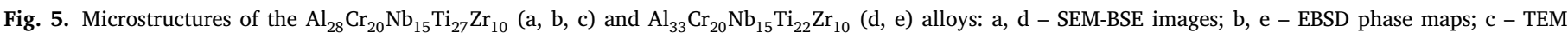
bright-field image and selected area electron diffraction pattern.

\section{Discussion}

\subsection{Predicted and experimental structures}

Our findings show that the CALPHAD method is a useful tool for developing ERHEAs based on the Al-Cr-Nb-Ti-Zr system. Table 3 summarizes experimental data on the alloys' phase compositions and the CALPHAD predictions derived from the Scheil model and equilibrium phase diagrams. The thermodynamic modeling is highly reliable in the case of Al-free alloys. The Scheil model and equilibrium phase diagrams correctly predicted the constitutive phases, their volume fraction, and types of as-solidified structures of the $\mathrm{Nb}_{30} \mathrm{Ti}_{40} \mathrm{Zr}_{30}$ and $\mathrm{Cr}_{20} \mathrm{Nb}_{30} \mathrm{Ti}_{40} \mathrm{Zr}_{20}$ alloys.

Some difference between the experiment and thermodynamic modeling arises in Al-containing alloys (Table 3). Neither the Scheil model nor the equilibrium phase diagrams predicted the B2 ordering of the bcc phase. Such CALPHAD's weakness has been extensively discussed elsewhere [43,59-61]. It was ascribed to the lack of the B2 phase description in binaries and ternaries containing $\mathrm{Al}$ and refractory elements [63]. The calculated volume fractions of the constitutive phases were also different from the experimental ones; for instance, the Laves phase's determined amount was significantly higher. This distinction can be associated with a complex, multicomponent chemical composition of the Laves phase particles (Table 1), while the CALPHAD predicts more evident partitioning of $\mathrm{Al}, \mathrm{Cr}$, and $\mathrm{Zr}$ to the Laves phase.

Simultaneously, the CALPHAD gave correct information about changing the Laves phase polytype from $\mathrm{C} 15$ (fcc) to $\mathrm{C} 14$ (hcp) when $\mathrm{Al}$ was added. But the more surprising was that, despite the above limitations, the CALPHAD prognosticated the type of the alloys' as-solidified structures very accurately. Usually, the CALPHAD is prone to under- or overestimate the eutectic point in E(R)HEAs that requires further experimental verification $[25,32,37]$. In the present study, the eutectic $\mathrm{Al}_{28} \mathrm{Cr}_{20} \mathrm{Nb}_{15} \mathrm{Ti}_{27} \mathrm{Zr}_{10}$ composition was successfully obtained without any additional experiments (Figs. 2a, b, and 5a-c; Table 3).

It is also worthy of analyzing the respective binary and ternary phase diagrams. In the Al-Cr-Nb-Ti-Zr system, four out of ten binaries have eutectic points, namely Al-Nb, Al-Zr, Cr-Zr, and Cr-Nb [64-67]. However, the absence of eutectic points in Al-Cr [68], $\mathrm{Nb}-\mathrm{Zr}$ [69], and $\mathrm{Ti}-\mathrm{X}$ ( $\mathrm{X}=\mathrm{Al}, \mathrm{Cr}, \mathrm{Nb}, \mathrm{Zr}$ ) [70-73] binaries suggests (in accord with the simple mixture approach [35], frequently used for 3d transition metals EHEAs) that there are no eutectic compositions in quinary Al-Cr-Nb-Ti-Zr system. Moreover, only in the $\mathrm{Cr}-\mathrm{Zr}$ and $\mathrm{Cr}-\mathrm{Nb}$ binaries, eutectics are composed of the bcc and Laves phases. The formation of eutectics containing bcc and/or C14 Laves phases is also observed in the Al-Nb-Cr and AlTi-Zr ternaries [74-77]. Finally, the ternary Al-Ti-Cr system is the sole system that has a description for both the B2 and C14 Laves phases, albeit no eutectic reaction between these phases is anticipated [78]. Thus, 


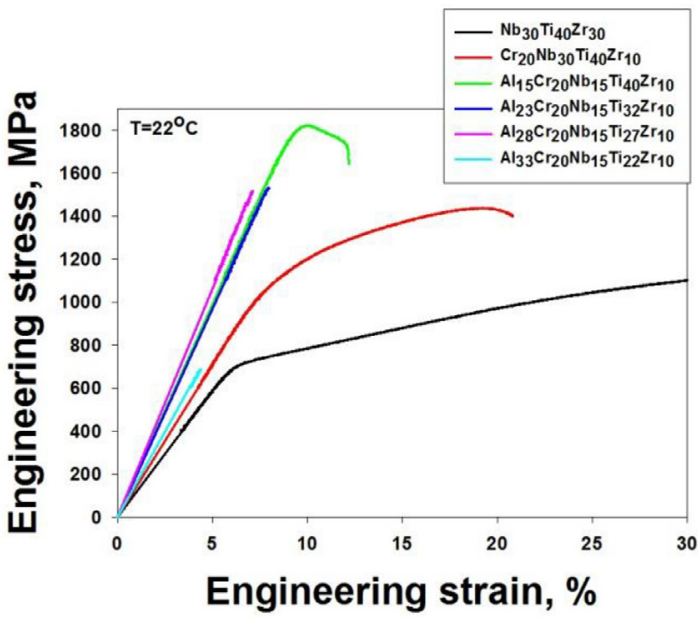

a

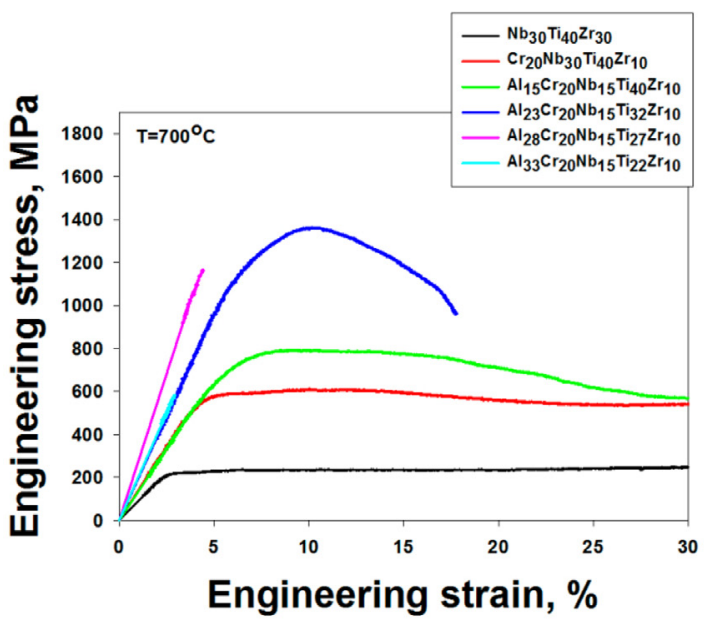

c

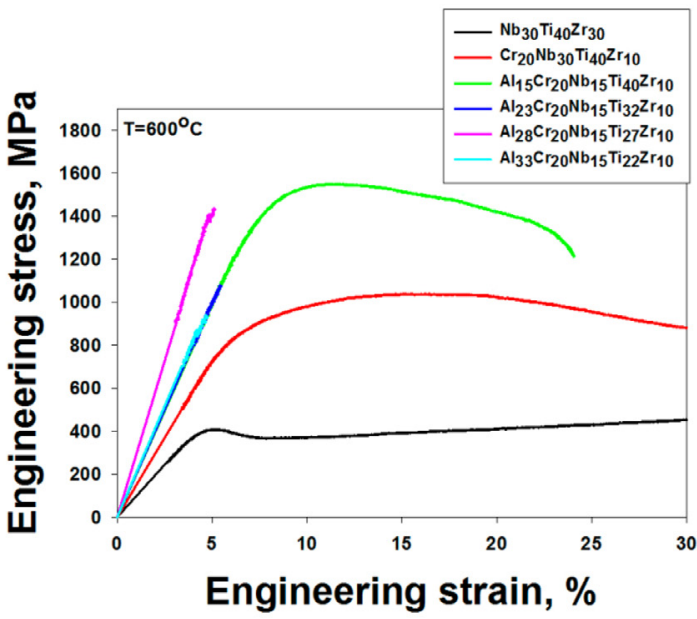

b

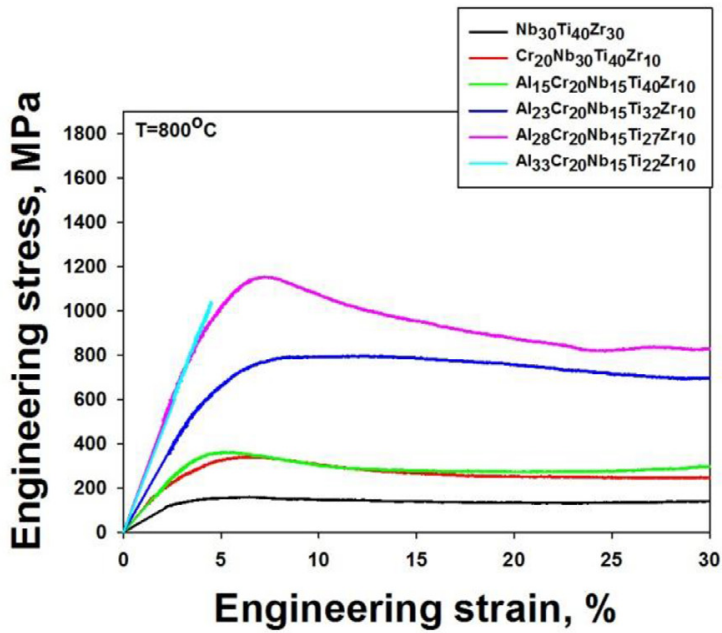

$\mathrm{d}$

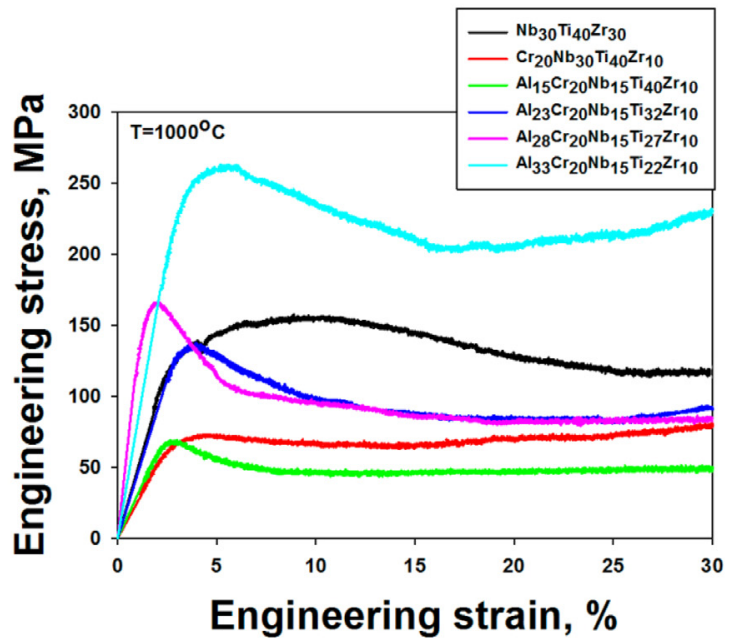

e

Fig. 6. Engineering stress-strain curves of the Al-Cr-Nb-Ti-Zr alloys obtained during the compression tests at 22 (a), 600 (b), 700 (c), 800 (d), and $1000{ }^{\circ} \mathrm{C}$ (e).

it can be suggested that the simultaneous presence of multiple elements is crucial for the B2/C14 Laves phase eutectic formation, while this type of structure is unattainable in simpler alloy systems.

Another interesting finding is that the proportional increase in $\mathrm{Al}$ (and decrease in $\mathrm{Ti}$ ) controls the type of structure in the investigated
RHEAs (Figs. 2, 4, 5). A similar relationship between the Al content and the as-solidified structure was previously found in the $\mathrm{Al}_{\mathrm{x}} \mathrm{CrNbTiZr}$ ERHEAs [33]. Yet, the nature of this phenomenon remains unclear. In contrast to strong Laves phase-formers such as $\mathrm{Cr}$ or $\mathrm{Zr}$, or solid solution providers, like $\mathrm{Ti}$ or $\mathrm{Nb}, \mathrm{Al}$ is almost evenly distributed between the 


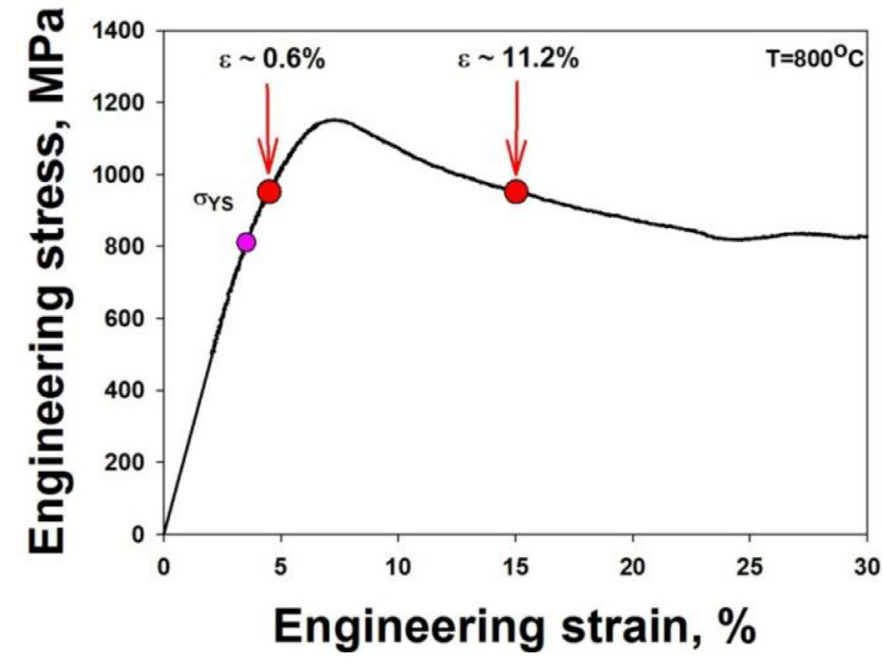

a

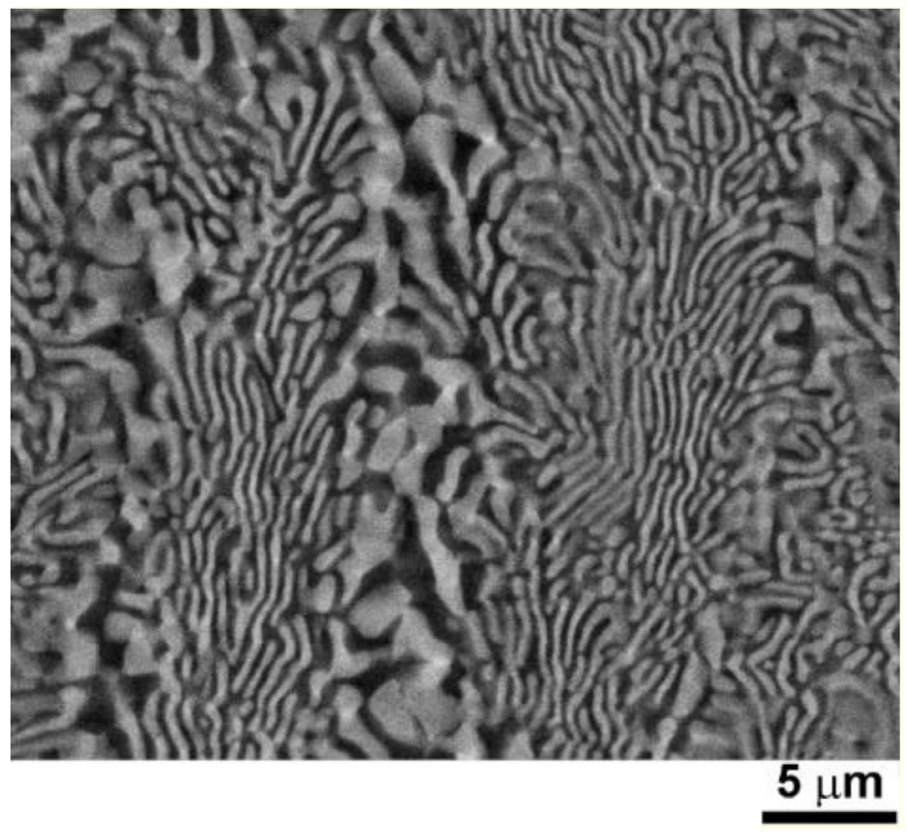

C

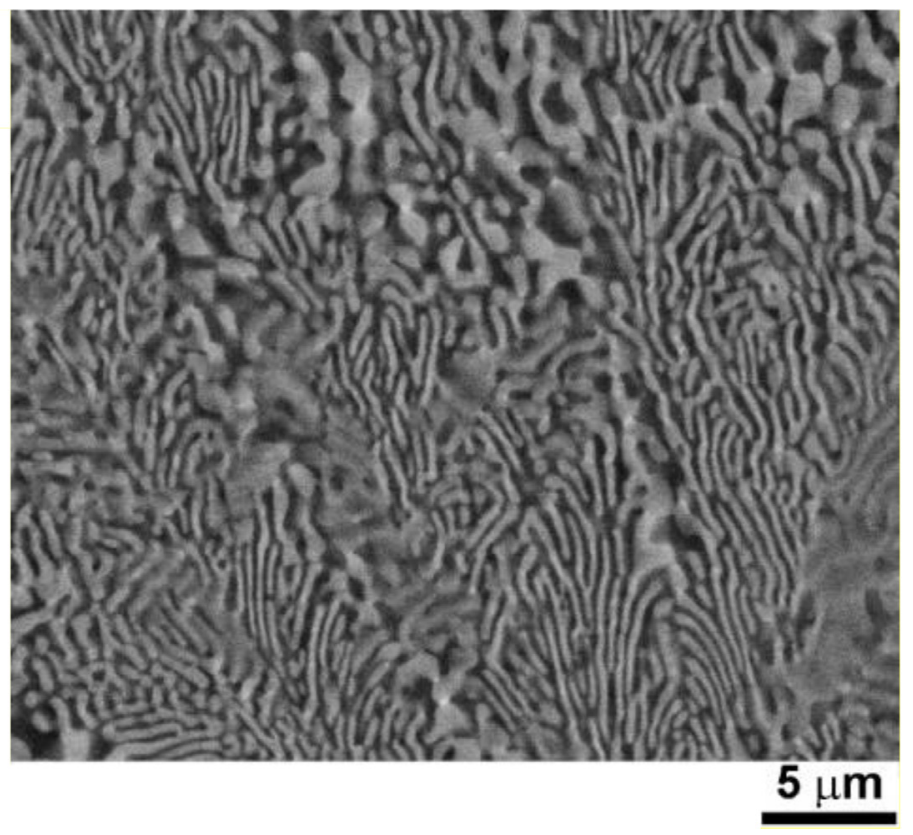

b

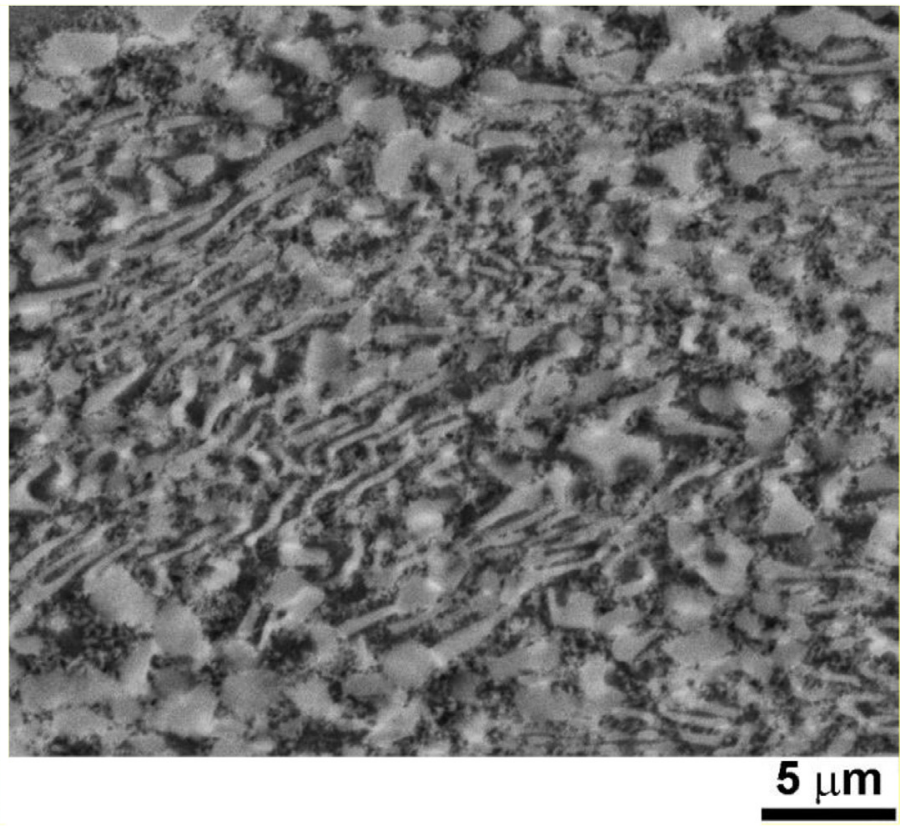

d

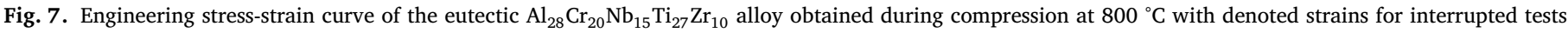
(a); microstructure of the $\mathrm{Al}_{28} \mathrm{Cr}_{20} \mathrm{Nb}_{15} \mathrm{Ti}_{27} \mathrm{Zr}_{10}$ alloy after compression to $\varepsilon \approx 0.6$ (b), 11.2\% (c), and 50\% (d) of height reduction: b-d - SEM-BSE images.

B2 and C14 Laves phases in the studied alloys (Table 1) (as well as in the $\mathrm{Al}_{\mathrm{x}} \mathrm{CrNbTiZr}$ ERHEAs [33]). Some explanations of the vital role of $\mathrm{Al}$ in creating eutectic structures can be found in the Al-Ti-Zr ternary [77]. A transformation from hypoeutectic to eutectic structure in the $\mathrm{Al}_{40} \mathrm{Ti}_{37} \mathrm{Zr}_{23}$ and $\mathrm{Al}_{45} \mathrm{Ti}_{33} \mathrm{Zr}_{22}$ alloys was connected with shifting from the primary precipitation region of the bcc phase towards the eutectic monovariant line in the liquidus projection. In the studied alloys, Al (in connection with $\mathrm{Ti}$ ) apparently switches the regions with primary solidification of either B2 or C14 Laves phases and monovariant eutectic formation.

Besides, it is known that the minimization of interfacial energy promotes the eutectic growth [79]. The minimum energy is usu- ally achieved at a small lattice mismatch. Due to the observed $(011)_{\mathrm{B} 2}||(10 \overline{1} 3)_{\mathrm{C} 14},[1 \overline{1} 1]_{\mathrm{B} 2}||[3 \overline{3} 0 \overline{1}]_{\mathrm{C} 14}$ OR (Fig. 5c), the lattice mismatch, $\delta$, between the $\mathrm{B} 2$ and $\mathrm{C} 14$ Laves phase can be calculated as follows [80]:

$\delta=\frac{2\left(d_{C 14 \text { Laves }}-d_{B 2}\right)}{\left(d_{C 14 \text { Laves }}-d_{B 2}\right)} * 100 \%$,

where $\mathrm{d}_{\mathrm{C} 14 \text { Laves }}=0.2335 \mathrm{~nm}$ and $\mathrm{d}_{\mathrm{B} 2}=0.2234 \mathrm{~nm}$ are the (1013) and (011) planes spacing of the C14 Laves and B2 phases, respectively. Recently, Cui et al. reported that Fe-Al-Ta eutectics nucleated below the critical value of $\delta=6 \%$ [80]. The lattice misfit for the eutectic $\mathrm{Al}_{28} \mathrm{Cr}_{20} \mathrm{Nb}_{15} \mathrm{Ti}_{27} \mathrm{Zr}_{10}$ alloy was estimated to be $4.4 \%$. Such a small mis- 


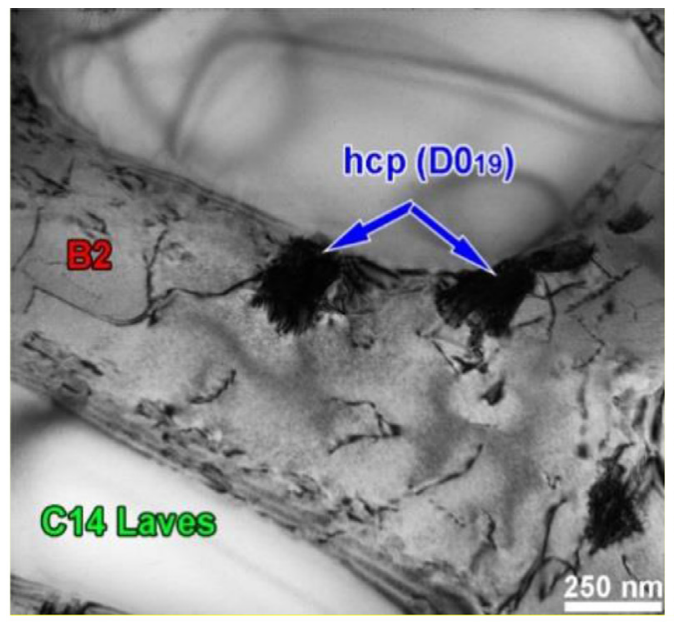

a

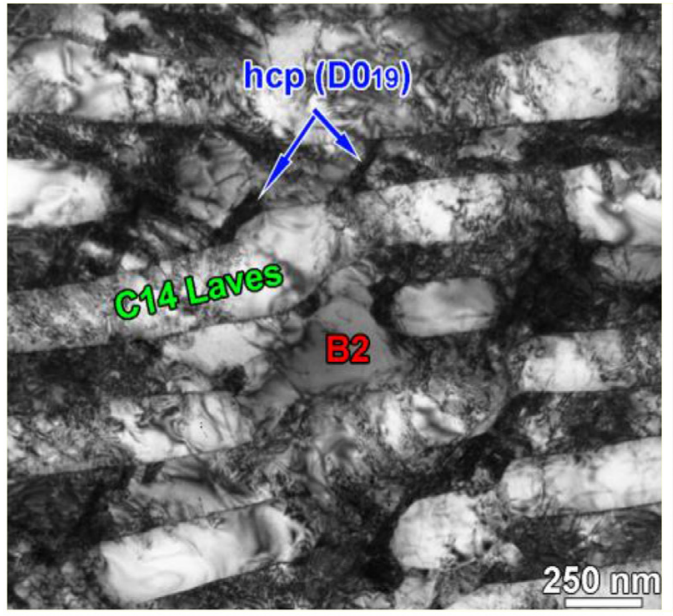

c

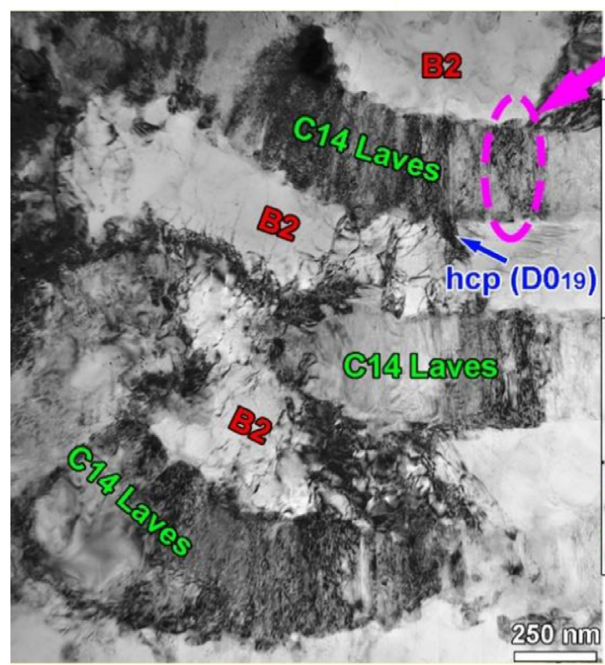

e

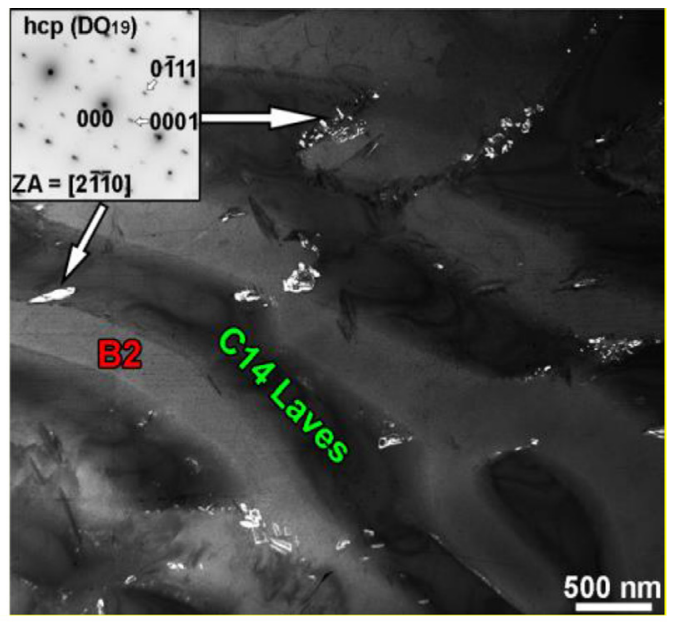

b

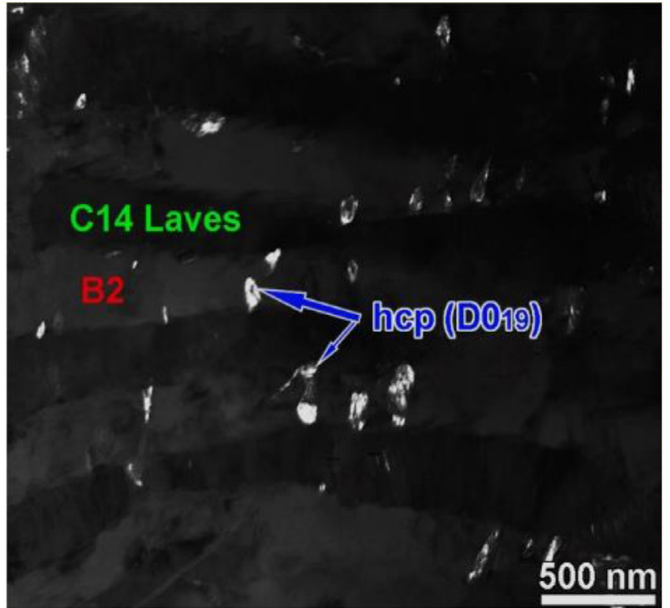

d

\section{Microband}

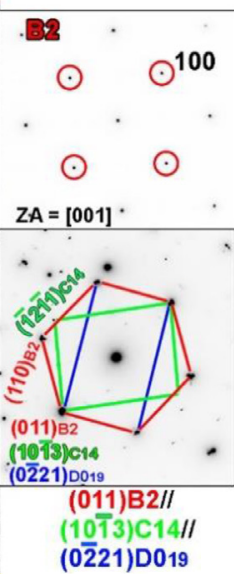

(0) 21$) \mathrm{D} 019$

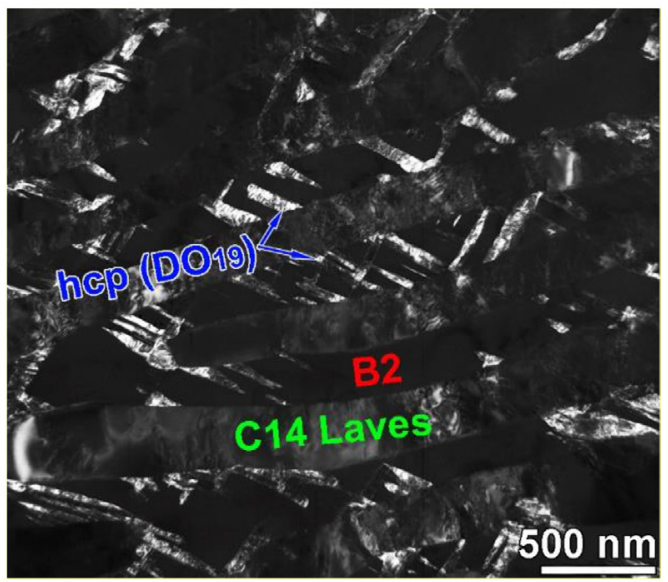

f

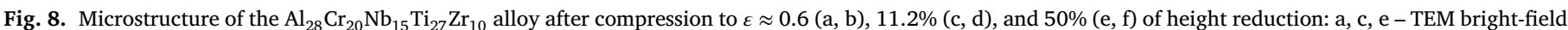

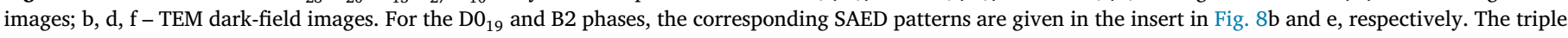
orientation relationship between the $\mathrm{B} 2, \mathrm{C} 14$ Laves, and $\mathrm{D}_{19}$ phases after compression to $\varepsilon \approx 50 \%$ is shown in the insert in Fig. $8 \mathrm{e}$. 


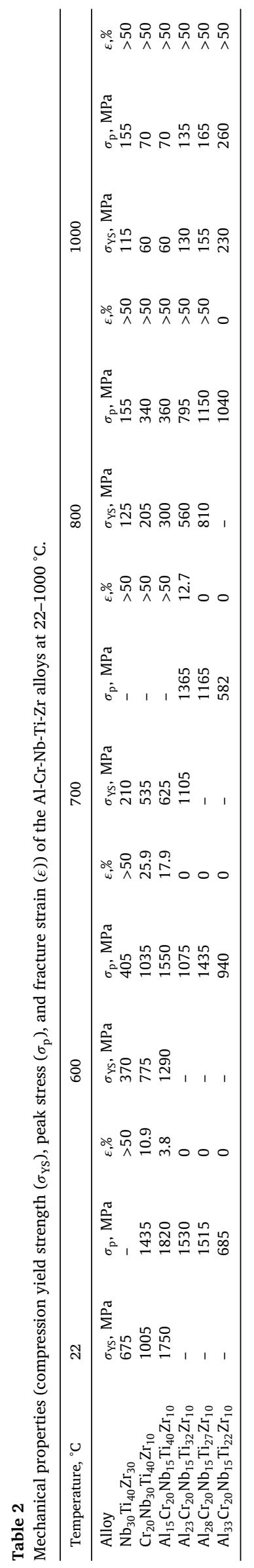

match between the B2 and C14 Laves phases ensured by the specific OR can indicate that the formation of eutectic B2/C14 Laves phase structure in the Al-Cr-Nb-Ti-Zr system is energetically favorable.

\subsection{Mechanical properties}

\subsection{1. $\mathrm{Nb}_{30} \mathrm{Ti}_{40} \mathrm{Zr}_{30}$ alloy}

One of the goals of the current study was to establish the structureproperty relationships of the investigated alloys in a wide temperature interval. As a baseline, we chose the single-phase bcc $\mathrm{Nb}_{30} \mathrm{Ti}_{40} \mathrm{Zr}_{30}$ alloy with presumably good ductility. Indeed, the alloy combined high compressive ductility and modest strength at room temperature (Fig. 6a, Table 2). To get additional insights into the deformation behavior of the alloy, tensile testing at room temperature was performed (Fig. 9a). $\mathrm{The}^{\mathrm{Nb}} \mathrm{b}_{30} \mathrm{Ti}_{40} \mathrm{Zr}_{30}$ alloy had a yield strength of $605 \mathrm{MPa}$ and decent ductility (elongation to fracture $-20.9 \%$ ) despite the lack of deformation hardening. Such mechanical behavior is typical of single bcc/B2 phase RHEAs [60,81-86].

Further, temperature increments did not affect the ductility but decreased the strength of the $\mathrm{Nb}_{30} \mathrm{Ti}_{40} \mathrm{Zr}_{30}$ alloy notably. The most significant softening occurred at $T<800{ }^{\circ} \mathrm{C}$, meanwhile at $T=800-1000{ }^{\circ} \mathrm{C}$, the strength remained almost unchanged (Fig. 6b-e, Table 2). Compared to the equiatomic, single-phase bcc NbTiZr alloy [41,87], the $\mathrm{Nb}_{30} \mathrm{Ti}_{40} \mathrm{Zr}_{30}$ alloy demonstrated considerably reduced strength at 22$800{ }^{\circ} \mathrm{C}$, which can be ascribed to a lower solid solution strengthening (Fig. 9b). Meanwhile, further in-depth studies are needed to reveal the factors affecting the mechanical behavior of the $\mathrm{Nb}_{30} \mathrm{Ti}_{40} \mathrm{Zr}_{30}$ and equiatomic NbTiZr alloys, especially in the high-temperature regime (Fig. 9b).

\subsubsection{Effect of Laves phase on strength}

The incorporation of the Laves phase, due to further alloying, alters the mechanical properties of the investigated alloys significantly. In terms of strength, the Laves phase operates as an effective reinforcement in numerous multiphase intermetallics alloys [88-90] and RHEAs [47,52,91,92]. In Fig. 10, the Laves phase's volume fraction $\left(\mathrm{V}_{\text {Laves }}\right)$ effect on the alloys' yield strength at different temperatures is shown.

In the interval of $22-700{ }^{\circ} \mathrm{C}$, the Laves phase induced a linear strength increment. Due to the similarity of slopes at 22 and $600{ }^{\circ} \mathrm{C}$, the Laves phase's strengthening ability seems insensitive to temperature growth in this interval. At temperatures $\leq 600{ }^{\circ} \mathrm{C}$, the yield strength increased by $30-35 \mathrm{MPa}$ with an addition of every 1 vol.\% of the Laves phase. This observation means that the alloys' strength reduction observed between 22 and $600{ }^{\circ} \mathrm{C}$ can be attributed to the softening of the bcc/B2 phase (Fig. 9b, for example). At $700{ }^{\circ} \mathrm{C}$, the Laves phase particles' hardening effect became less pronounced: the yield strength increment was only $17 \mathrm{MPa} / \mathrm{vol} \%$. It can suggest that despite some softening of the Laves phase, the strength additivity between the constitutive phases is retained. Another important and unexpected finding is that the bcc-B2 transition due to the $\mathrm{Al}$ addition seems to have a weak effect on the macroscopic strength of the alloys at $T \leq 700^{\circ} \mathrm{C}$ since the yield strength is proportional to the Laves phase's fraction.

However, the linear relationship broke at $800{ }^{\circ} \mathrm{C}$ (Fig. 10), and more complex dependence is observed that can be described using the following equation:

$\sigma_{Y S}=87.765+52.349 e^{\left(0.046 V_{\text {Laves }}\right)}$

According to Eq. (2), the Laves phase particles' reinforcement becomes dominant at only $\mathrm{V}_{\text {Laves }} \geq 31 \%$. When the Laves phase's fraction is higher than the threshold value, its strengthening ability quickly increases. Such a complex effect of the Laves phase on the strength suggests contributions of additional factors, among which the structure morphology can be decisive. Specifically, the fine lamellar microstructure with multiple interfaces between the "soft" bcc/B2 and "hard" Laves phases produces the long-range back stresses (Fig. 8) [29] that should constrain plastic deformation in the eutectic regions. The back stress 


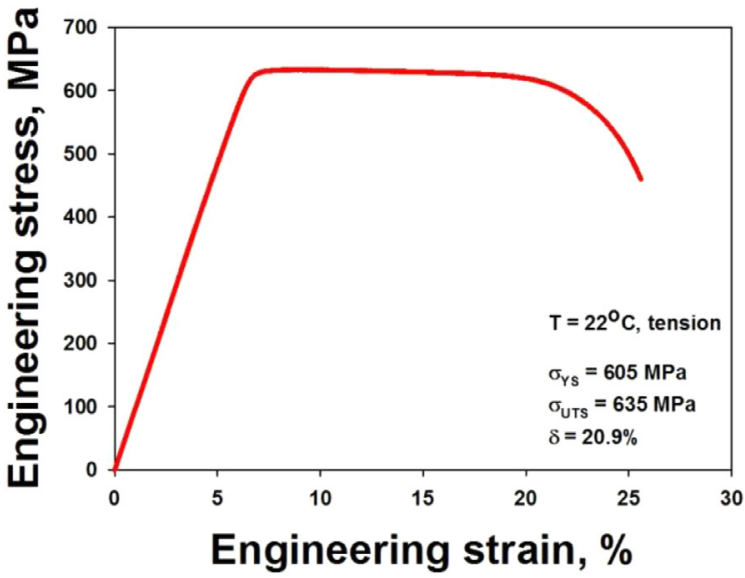

a

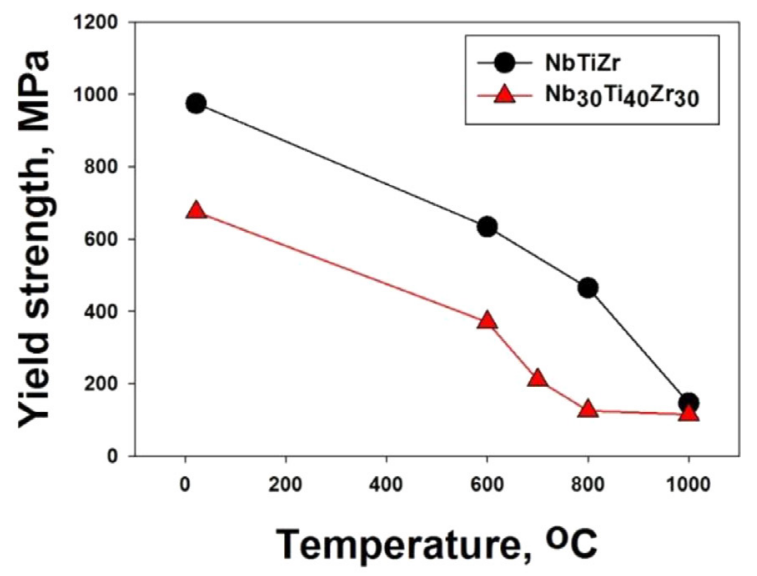

b

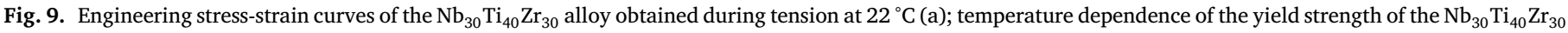
and equiatomic NbTiZr [41,87] alloys (b).

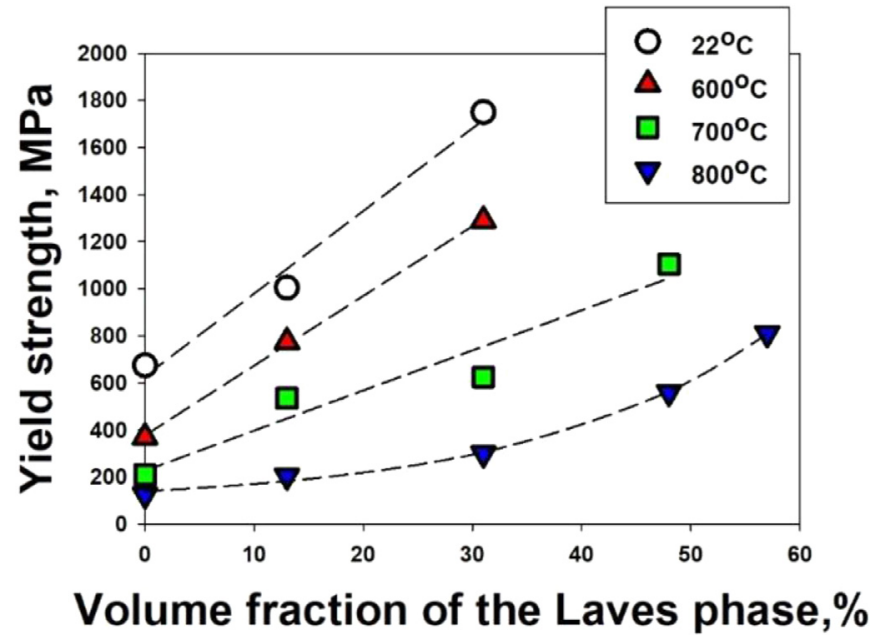

Fig. 10. Yield strength of the Al-Cr-Nb-Ti-Zr alloys as a function of the volume fraction of the Laves phase at different temperatures. The dashed lines in the figure are drawn only to guide the eye.

also exists in the proeutectic regions, but its level is not enough to prevent the dislocation motion in the "soft" bcc/B2 phase due to relatively large distances between the "hard" Laves phase particles. Consequently, the substitution of the low-constraint proeutectic bcc/B2 phase with the high-constraint eutectic mixture is likely responsible for the exponentlike strength enlargement observed with the increase in the Laves phase' volume fraction (Fig. 10).

Remarkable softening of the studied alloys at $1000{ }^{\circ} \mathrm{C}$ (Fig. 6e) can be ascribed to disordering, phase transformations, dynamic recrystallization and/or globularization of eutectic lamellae. Detailed analysis of these questions is beyond the current work scope; however, some aspects of the microstructure evolution during hot deformation will be discussed in Section 5.3.

\subsubsection{Effect of structure on ductility}

It is known that a rapid strength increment due to the Laves phase is usually accompanied by a drastic drop of ductility [47,88-91]. That is why the relationship shown in Fig. 10 covers a limited range of the Laves phase's volume fraction. Only the hypoeutectic alloys containing less than $31-48 \%$ of the Laves phase reached the yield point at ambient temperature. Meanwhile, the ductility of the Al-containing alloys with 48$66 \%$ of the Laves phase was nearly zero at room temperature; the brittle- to-ductile transition occurred in the temperature range of $700-1000{ }^{\circ} \mathrm{C}$ (Table 2). This behavior is typical for the Laves phase-strengthened alloys $[47,55,91]$. Some ductility improvement (at a given Laves phase's volume fraction) can be achieved by controlling the degree of $\mathrm{B} 2$ ordering. Previous works on the Al-Nb-Ti-V-Zr or Al-Cr-Mo-Ti alloys demonstrated that a decrease in the $\mathrm{Al}$ content and, consequently, production of "less ordered" B2 structure resulted in good tensile or compressive ductility while maintaining good high-temperature strength $[55,57,60]$. However, in the case of the studied alloys, the existence of the eutectic B2/C14 Laves phase structure is closely related to $\mathrm{Al}$ content (Figs. 4, 5). Thus, further tailoring of the chemical composition of eutectic or near-eutectic RHEAs based on the Al-Cr-Nb-Ti-Zr system is needed to get better strength-ductility synergy.

Nevertheless, the studied alloys with the hypoeutectic structure already exhibited rather balanced mechanical performance. One of the promising examples of such alloys was the $\mathrm{Al}_{15} \mathrm{Cr}_{20} \mathrm{Nb}_{15} \mathrm{Ti}_{40} \mathrm{Zr}_{10}$ alloy. It showed somewhat room-temperature ductility and high strength in the interval of $22-600{ }^{\circ} \mathrm{C}$ (Table 2). Moreover, the alloy retained a reasonable strength at $700{ }^{\circ} \mathrm{C}$ before softening at $T \geq 800{ }^{\circ} \mathrm{C}$. Considering its density ( $5.55 \mathrm{~g} / \mathrm{cm}^{3}$; Fig. S2a), the specific yield strength of the alloy varied from exceptionally high values of 315 and $232 \mathrm{kPa} \mathrm{m}^{3} \mathrm{~kg}^{-1}$ at 22 and $600{ }^{\circ} \mathrm{C}$, respectively, to $112 \mathrm{kPa} \mathrm{m}^{3} \mathrm{~kg}^{-1}$ at $700{ }^{\circ} \mathrm{C}$. It is believed that further optimization of the alloy's structure to increase the ductility at ambient temperature would make it an attractive candidate with a high weight-to-strength ratio for potential applications at $600-700{ }^{\circ} \mathrm{C}$.

\subsection{High-temperature mechanical behavior of the eutectic B2/C14 Laves phase structure}

Up to date, only a few attempts have been made to elucidate the mechanical behavior and deformation mechanisms of RHEAs at high temperatures [93-99]. Most of these studies were devoted to single- or nearly single-phase compositions [93-98]. Similar information on multiphase alloys is mostly lacking. Therefore, the microstructure evolution of the eutectic $\mathrm{Al}_{28} \mathrm{Cr}_{20} \mathrm{Nb}_{15} \mathrm{Ti}_{27} \mathrm{Zr}_{10}$ alloy during deformation at $800^{\circ} \mathrm{C}$ was studied in detail.

During compression, the alloy yielded at $810 \mathrm{MPa}$ and then rapidly strengthened to the peak value of $1150 \mathrm{MPa}$, followed by a pronounced softening stage and an extended steady flow (Figs. 6d, 7a). Such a strain hardening-softening "hump" is usually associated with dynamic recrystallization [100]. However, a close examination of the microstructure after deformation (Figs. $\mathbf{7 b}$-d, 8) revealed that the observed mechanical behavior could be ascribed to the partitioning of plastic flow between a "soft" (B2) and a "hard" (Laves) phase. At the strain hardening stage, the plastic deformation localized in the B2 phase (Figs. 8a, 11a). The C14 

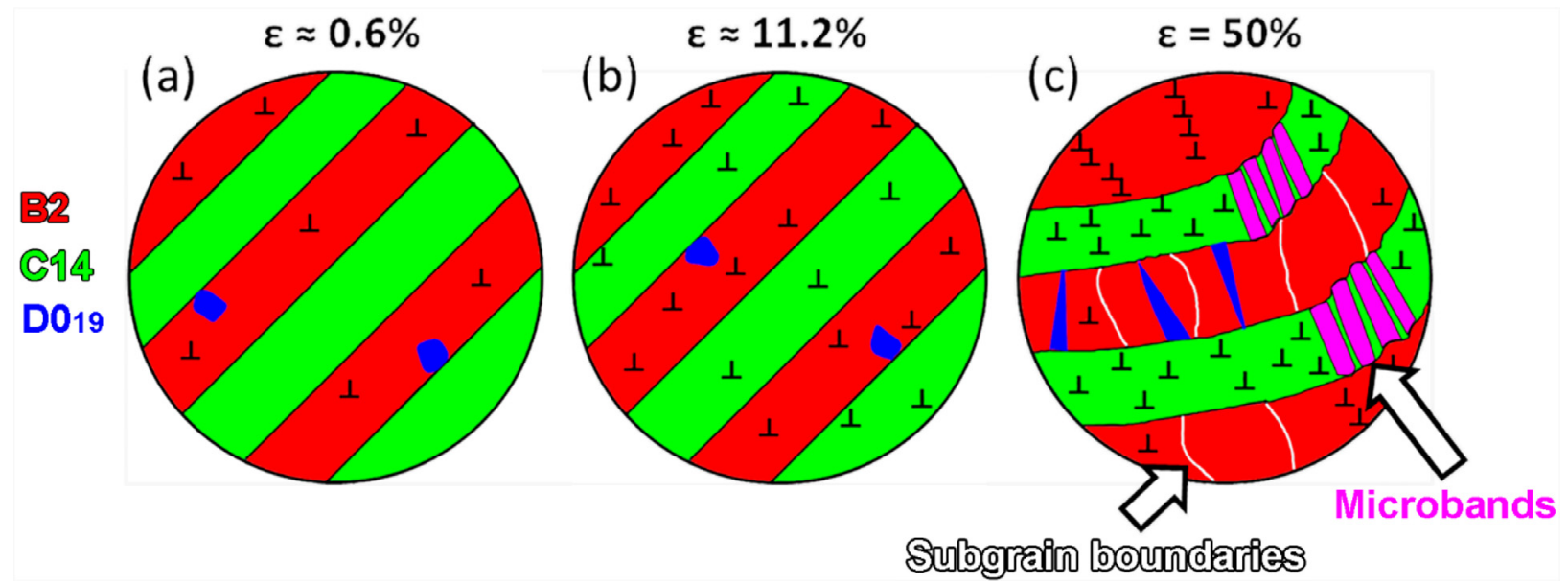

Fig. 11. Schematic representation showing microstructure evolution during compression of the eutectic $\mathrm{Al}_{28} \mathrm{Cr}_{20} \mathrm{Nb}_{15} \mathrm{Ti}_{27} \mathrm{Zr}_{10}$ alloy. The compression axis is vertical.

Table 3

Data on experimental and predicted phases, their volume fraction $\left(\mathrm{V}_{\mathrm{f}}\right)$, and type of as-solidified structure (TAS) of the Al-Cr-Nb-Ti-Zr alloys.

\begin{tabular}{|c|c|c|c|c|c|c|c|c|c|}
\hline \multirow[t]{2}{*}{ Alloy } & \multicolumn{3}{|c|}{ Experimental } & \multicolumn{3}{|c|}{ Scheil model } & \multicolumn{3}{|c|}{ Equilibrium phase diagram } \\
\hline & Phase & $V_{f}, \%$ & TAS & Phase & $V_{f}, \%$ & TAS & Phase* & $\mathrm{V}_{\mathrm{f}}, \%$ & TAS \\
\hline $\mathrm{Nb}_{30} \mathrm{Ti}_{40} \mathrm{Zr}_{30}$ & bcc & 100 & $\begin{array}{l}\text { single- } \\
\text { phase }\end{array}$ & bcc & 100 & $\begin{array}{l}\text { single- } \\
\text { phase }\end{array}$ & bcc & 100 & $\begin{array}{l}\text { single- } \\
\text { phase }\end{array}$ \\
\hline \multirow{2}{*}{$\mathrm{Cr}_{20} \mathrm{Nb}_{30} \mathrm{Ti}_{40} \mathrm{Zr}_{10}$} & $\mathrm{bcc}$ & 86 & hypoeutectic & bcc & 88 & hypoeutectic & $\mathrm{bcc}$ & 95 & hypoeutectic \\
\hline & C15 & 14 & & C15 & 12 & & $\mathrm{C} 15$ & 5 & \\
\hline \multirow{3}{*}{$\mathrm{Al}_{15} \mathrm{Cr}_{20} \mathrm{Nb}_{15} \mathrm{Ti}_{40} \mathrm{Zr}_{10}$} & B2 & 67 & hypoeutectic & $\mathrm{bcc}$ & 93.6 & hypoeutectic & bcc & 99 & hypoeutectic \\
\hline & & & & C14 & 6 & & & & \\
\hline & C14 & 33 & & C15 & 0.4 & & C14 & 1 & \\
\hline \multirow{2}{*}{$\mathrm{Al}_{23} \mathrm{Cr}_{20} \mathrm{Nb}_{15} \mathrm{Ti}_{32} \mathrm{Zr}_{10}$} & B2 & 53 & hypoeutectic & $\mathrm{bcc}$ & 87 & hypoeutectic & bcc & 88 & hypoeutectic \\
\hline & C14 & 47 & & C14 & 13 & & $\mathrm{C} 14$ & 12 & \\
\hline \multirow[t]{2}{*}{$\mathrm{Al}_{28} \mathrm{Cr}_{20} \mathrm{Nb}_{15} \mathrm{Ti}_{27} \mathrm{Zr}_{10}$} & B2 & 44 & eutectic & bcc & 76 & eutectic & bcc & 76 & eutectic \\
\hline & C14 & 56 & & C14 & 24 & & $\mathrm{C} 14$ & 24 & \\
\hline \multirow[t]{2}{*}{$\mathrm{Al}_{33} \mathrm{Cr}_{20} \mathrm{Nb}_{15} \mathrm{Ti}_{22} \mathrm{Zr}_{10}$} & B2 & 38 & hypereutectic & $\mathrm{bcc}$ & 60 & hypereutectic & $\mathrm{bcc}$ & 60 & hypereutectic \\
\hline & C14 & 62 & & C14 & 40 & & C14 & 40 & \\
\hline
\end{tabular}

* in the case of equilibrium calculations, the phases and their volume fractions were estimated immediately after crystallization.

Laves phase lamellae, almost unaffected by plastic deformation, effectively confined the dislocation slip within the B2 phase lamellae, thereby increasing the flow stress. After exceeding the peak stress, further accommodation of plastic deformation became possible only through the plastic flow initiation in the C14 Laves phase (Figs. 8c, 11b). However, this process led to a notable softening induced by thermally activated dislocation slip, which was observed early in binary and ternary Lavesbased/contained alloys [88,101,102].

Later stages of deformation were attended by the substructure formation in the B2 lamellae along with microbanding and bending the C14 Laves phase lamellae (Figs. 7d, 8e, 11c). Judging by the serrations on the B2/C14 interfaces, the bending can be caused by local shear deformation in the transversal microbands, however, without further lamellae fragmentation (at least till $\varepsilon \approx 50 \%$ ). Moreover, the lamellae rearrangement at high strain did not lead to losing the OR between the B2 and C14 Laves phases (see the insert in Fig. 8e). The survived OR allows saving the low-energy interfaces that can explain the absence of fragmentation and/or globularization/coalescence of lamellae even after rather a large deformation to $50 \%$ of height reduction [103].

Deformation of the eutectic $\mathrm{Al}_{28} \mathrm{Cr}_{20} \mathrm{Nb}_{15} \mathrm{Ti}_{27} \mathrm{Zr}_{10}$ alloy at $800^{\circ} \mathrm{C}$ was also associated with the precipitation of the $\mathrm{D}_{19}$ phase particles. The formation of this phase was in fair agreement with the thermodynamic data (Fig. 2a). However, the predicted $\mathrm{D}_{19}$ phase was expected to precipitate at $T \leq 700^{\circ} \mathrm{C}$ and to have an almost stoichiometric phase composition of $\mathrm{Ti}_{3} \mathrm{Al}$. According to EDS analysis, the experimental $\mathrm{D} 0_{19}$ phase had a chemical composition of $\mathrm{Al}_{28} \mathrm{Cr}_{5} \mathrm{Nb}_{18} \mathrm{Ti}_{45} \mathrm{Zr}_{4}$ after $\varepsilon \approx 0.6 \%$ or $11.2 \%$ and $\mathrm{Al}_{28} \mathrm{Cr}_{4} \mathrm{Nb}_{14} \mathrm{Ti}_{51} \mathrm{Zr}_{3}$ after $\varepsilon=50 \%$. The chemical composi- tion could be expressed as a cluster formula (Ti, Nb, Cr, $\mathrm{Zr}_{72} \mathrm{Al}_{28} \approx$ $\mathrm{Ti}_{3} \mathrm{Al}$.

In the studied eutectic alloy, the $\mathrm{DO}_{19}$ phase appeared at the very beginning of deformation as irregular-shaped particles nucleated predominantly on the B2/C14 interfaces and located in the B2 lamellae (Fig. 8b). Since the volume fraction of the $\mathrm{D}_{19}$ particles was very low $(\sim 3 \%)$ even after $\varepsilon \approx 11.2 \%$, they can hardly be considered as effective obstacles for the dislocation motion (Fig. 8d). Meanwhile, after $50 \%$ of strain, the $\mathrm{D}_{19}$ phase transformed into needle-shaped particles divided the B2 lamellae (Fig. 8f). The specific OR between the B2, C14 Laves, and $\mathrm{D}_{19}$ phases could be the most probable reason for such particles' form. According to Eq. (1), the lattice misfit between the $\mathrm{B} 2$ and $\mathrm{D}_{19}$ is $1.3 \%$, while for the $\mathrm{D}_{19}$ and $\mathrm{C} 14$ Laves phases $-5.7 \%$. Better crystallographic matching and higher Ti content (Table 1) made the propagation of the $\mathrm{D}_{19}$ needles in the $\mathrm{B} 2$ phase more preferential than in the $\mathrm{C} 14$ Laves phase. Considering the high strength and creep resistance of the $\mathrm{Ti}_{3} \mathrm{Al}$ phase [104], a much stronger at elevated temperatures structure composed of the $\mathrm{B} 2 / \mathrm{C} 14$ lamellae with the embedded $\mathrm{D} 0_{19}$ needles can be created in ERHEAs by proper heat treatment.

\section{Conclusions}

In this study, a series of Al-Cr-Nb-Ti-Zr (E)RHEAs was designed using the CALPHAD approach, and their composition-structure-property relationships and deformation mechanisms were studied. The following conclusions were made: 
1 The CALPHAD (the Thermo-Calc software equipped with the TCHEA3 database) approach was able to identify various structures in the Al-Cr-Nb-Ti-Zr system, some of them unexpected in simpler systems. It correctly predicted the single-phase bcc $\mathrm{Nb}_{30} \mathrm{Ti}_{40} \mathrm{Zr}_{30}$ and hypoeutectic bcc/C15 Laves phase $\mathrm{Cr}_{20} \mathrm{Nb}_{30} \mathrm{Ti}_{40} \mathrm{Zr}_{10}$ alloys. The hypo- $\left(\mathrm{Al}_{15} \mathrm{Cr}_{20} \mathrm{Nb}_{15} \mathrm{Ti}_{40} \mathrm{Zr}_{10}\right.$ and $\mathrm{Al}_{23} \mathrm{Cr}_{20} \mathrm{Nb}_{15} \mathrm{Ti}_{32} \mathrm{Zr}_{10}$ ), hyper- $\left(\mathrm{Al}_{33} \mathrm{Cr}_{20} \mathrm{Nb}_{15} \mathrm{Ti}_{22} \mathrm{Zr}_{10}\right)$, and eutectic $\left(\mathrm{Al}_{28} \mathrm{Cr}_{20} \mathrm{Nb}_{15} \mathrm{Ti}_{27} \mathrm{Zr}_{10}\right)$ B2/C14 Laves phase alloys were also successfully designed by the CALPHAD, despite some uncertainties related to the B2 ordering and the Laves phase amount.

2 The alloys' strength increased from the single-phase to the dualphase eutectic-like microstructure, whilst the B2 ordering had a weak effect. The Laves phase linearly enlarged the compressive yield strength below $700{ }^{\circ} \mathrm{C}$. At $800{ }^{\circ} \mathrm{C}$, an exponential strength growth was found, ascribed to the rising back stresses with approaching the fully eutectic structure. All alloys softened substantially at $1000{ }^{\circ} \mathrm{C}$.

3 The Al-Cr-Nb-Ti-Zr alloys ductility decreased as the strength increased. The single-phase bcc $\mathrm{Nb}_{30} \mathrm{Ti}_{40} \mathrm{Zr}_{30}$ alloy showed excellent compressive and tensile ductility at room temperature. Meanwhile, the hypoeutectic $\mathrm{Al}_{23} \mathrm{Cr}_{20} \mathrm{Nb}_{15} \mathrm{Ti}_{32} \mathrm{Zr}_{10}$, eutectic $\mathrm{Al}_{28} \mathrm{Cr}_{20} \mathrm{Nb}_{15} \mathrm{Ti}_{27} \mathrm{Zr}_{10}$, and hypereutectic $\mathrm{Al}_{33} \mathrm{Cr}_{20} \mathrm{Nb}_{15} \mathrm{Ti}_{22} \mathrm{Zr}_{10}$ alloys had the brittle-to-ductile transition in the temperature range of $700-1000^{\circ} \mathrm{C}$.

4 The microstructure evolution during compression of the eutectic $\mathrm{Al}_{28} \mathrm{Cr}_{20} \mathrm{Nb}_{15} \mathrm{Ti}_{27} \mathrm{Zr}_{10}$ alloy at $800{ }^{\circ} \mathrm{C}$ was examined. At the strain hardening stage, plastic deformation was caused by the dislocation motion inside the "soft" B2 lamellae. After achieving the peak value, the flow stress notably reduced, which was associated with the activation of plastic deformation in the "hard" C14 Laves phase lamellae. At higher strains, the substructure formation in the B2 lamellae and microbanding inside the C14 Laves phase lamellae alongside their bending were found. The resistance of the lamellar B2/C14 microstructure to fragmentation during plastic deformation was attributed to maintaining the initial $(011)_{\mathrm{B} 2} \|(10 \overline{1} 3)_{\mathrm{C} 14}$, $[1 \overline{1} 1]_{\mathrm{B} 2}||[3 \overline{3} 0 \overline{1}]_{\mathrm{C} 14}$ OR that ensured a small lattice mismatch and low interfacial energy.

5 Compression at $800{ }^{\circ} \mathrm{C}$ also led to forming a new, Ti-rich phase with an ordered hexagonal $\left(\mathrm{D}_{19}\right)$ structure having a specific $(011)_{\mathrm{B} 2}||(10 \overline{1} 3)_{\mathrm{C} 14} \|(0 \overline{2} 21)_{\mathrm{D} 019}$ OR. This phase precipitated inside the B2 lamellae adjacent to the B2/C14 Laves phase interfaces from the beginning of plastic deformation.

\section{Declaration of Competing Interest}

The authors declare that they have no known competing financial interests or personal relationships that could have appeared to influence the work reported in this paper.

\section{Acknowledgments}

The authors gratefully acknowledge the financial support from the Russian Science Foundation Grant no. 19-79-30066. The authors are grateful to the personnel of the Joint Research Center, "Technology and Materials", Belgorod National Research University, for their assistance. The authors would like to extend acknowledgements to Dr. D. Shaysultanov of Laboratory of Bulk Nanostructured Materials, Belgorod National Research University, for his help in the preparation of the ingots.

\section{Supplementary materials}

Supplementary material associated with this article can be found, in the online version, at doi:10.1016/j.mtla.2021.101057.

\section{References}

[1] J.W. Yeh, S.K. Chen, S.J. Lin, J.Y. Gan, T.S. Chin, T.T. Shun, C.H. Tsau, S.Y. Chang, Nanostructured high-entropy alloys with multiple principal elements: novel al- loy design concepts and outcomes, Adv. Eng. Mater. 6 (2004) 299-303 +274, doi:10.1002/adem.200300567.

[2] D.B. Miracle, O.N. Senkov, A critical review of high entropy alloys and related concepts, Acta Mater. 122 (2017) 448-511, doi:10.1016/j.actamat.2016.08.081.

[3] E.P. George, D. Raabe, R.O. Ritchie, High-entropy alloys, Nat. Rev. Mater. 4 (2019) 515-534, doi:10.1038/s41578-019-0121-4.

[4] E.P. George, W.A. Curtin, C.C. Tasan, High entropy alloys: a focused review of mechanical properties and deformation mechanisms, Acta Mater. (2019), doi:10.1016/j.actamat.2019.12.015

[5] J.Y. He, H. Wang, H.L. Huang, X.D. Xu, M.W. Chen, Y. Wu, X.J. Liu, T.G. Nieh, K. An, Z.P. Lu, A precipitation-hardened high-entropy alloy with outstanding tensile properties, Acta Mater. 102 (2016) 187-196, doi:10.1016/J.ACTAMAT.2015.08.076.

[6] W.H. Liu, Z.P. Lu, J.Y. He, J.H. Luan, Z.J. Wang, B. Liu, Y. Liu, M.W. Chen, C.T. Liu, Ductile CoCrFeNiMo $\mathrm{x}_{\mathrm{x}}$ high entropy alloys strengthened by hard intermetallic phases, Acta Mater. 116 (2016) 332-342, doi:10.1016/j.actamat.2016.06.063.

[7] Y.J. Liang, L. Wang, Y. Wen, B. Cheng, Q. Wu, T. Cao, Q. Xiao, Y. Xue, G. Sha Y. Wang, Y. Ren, X. Li, L. Wang, F. Wang, H. Cai, High-content ductile coherent nanoprecipitates achieve ultrastrong high-entropy alloys, Nat. Commun. 9 (2018) 1-8, doi:10.1038/s41467-018-06600-8.

[8] T. Yang, Y.L. Zhao, Y. Tong, Z.B. Jiao, J. Wei, J.X. Cai, X.D. Han, D. Chen, A. Hu, J.J. Kai, K. Lu, Y. Liu, C.T. Liu, Multicomponent intermetallic nanoparticles and superb mechanical behaviors of complex alloys, Science 362 (80) (2018) 933-937, doi:10.1126/science.aas8815.

[9] K. Ming, X. Bi, J. Wang, Realizing strength-ductility combination of coarse-grained $\mathrm{Al}_{0.2} \mathrm{Co}_{1.5} \mathrm{CrFeNi}_{1.5} \mathrm{Ti}_{0.3}$ alloy via nano-sized, coherent precipitates, Int. J. Plast. 100 (2018) 177-191, doi:10.1016/J.IJPLAS.2017.10.005.

[10] I. Baker, M. Wu, Z. Wang, Eutectic/eutectoid multi-principle component alloys: a review, Mater. Charact. 147 (2019) 545-557, doi:10.1016/J.MATCHAR.2018.07.030.

[11] B. Chanda, G. Potnis, P.P. Jana, J. Das, A review on nano-/ultrafine advanced eutectic alloys, J. Alloy. Compd. (2020) 154226, doi:10.1016/j.jallcom.2020.154226.

[12] Y. Lu, Y. Dong, H. Jiang, Z. Wang, Z. Cao, S. Guo, T. Wang, T. Li, P.K. Liaw, Promising properties and future trend of eutectic high entropy alloys, Scr. Mater. 187 (2020) 202-209, doi:10.1016/j.scriptamat.2020.06.022.

[13] Y. Lu, Y. Dong, S. Guo, L. Jiang, H. Kang, T. Wang, B. Wen, Z. Wang, J. Jie, Z. Cao, H. Ruan, T. Li, A promising new class of high-temperature alloys: eutectic highentropy alloys, Sci. Rep. 4 (2014) 1-5, doi:10.1038/srep06200.

[14] Y. Lu, X. Gao, L. Jiang, Z. Chen, T. Wang, J. Jie, H. Kang, Y. Zhang, S. Guo, H. Ruan, Y. Zhao, Z. Cao, T. Li, Directly cast bulk eutectic and near-eutectic high entropy alloys with balanced strength and ductility in a wide temperature range, Acta Mater. 124 (2017) 143-150, doi:10.1016/j.actamat.2016.11.016.

[15] T. Bhattacharjee, R. Zheng, Y. Chong, S. Sheikh, S. Guo, I.T. Clark, T. Okawa, I.S. Wani, P.P. Bhattacharjee, A. Shibata, N. Tsuji, Effect of low temperature on tensile properties of $\mathrm{AlCoCrFeNi}_{21}$ eutectic high entropy alloy, Mater. Chem. Phys. 210 (2018) 207-212, doi:10.1016/j.matchemphys.2017.06.023.

[16] A. Lozinko, Y. Zhang, O.V. Mishin, U. Klement, S. Guo, Microstructural characterization of eutectic and near-eutectic AlCoCrFeNi high-entropy alloys, J. Alloy. Compd. 822 (2020) 153558, doi:10.1016/j.jallcom.2019.153558.

[17] Q. Wu, Z. Wang, T. Zheng, D. Chen, Z. Yang, J. Li, J. jung Kai, J. Wang, A casting eutectic high entropy alloy with superior strength-ductility combination, Mater. Lett. 253 (2019) 268-271, doi:10.1016/j.matlet.2019.06.067.

[18] Y. Dong, Z. Yao, X. Huang, F. Du, C. Li, A. Chen, F. Wu, Y. Cheng, Z. Zhang, Microstructure and mechanical properties of $\mathrm{AlCo}_{\mathrm{x}} \mathrm{CrFeNi}_{3-\mathrm{x}}$ eutectic high-entropy-alloy system, J. Alloy. Compd. 823 (2020) 153886, doi:10.1016/j.jallcom.2020.153886.

[19] X. Jin, J. Bi, L. Zhang, Y. Zhou, X. Du, Y. Liang, B. Li, A new $\mathrm{CrFeNi}_{2} \mathrm{Al}$ eutectic high entropy alloy system with excellent mechanical properties, J. Alloy. Compd. 770 (2019) 655-661, doi:10.1016/j.jallcom.2018.08.176.

[20] X. Jin, Y. Zhou, L. Zhang, X. Du, B. Li, A novel $\mathrm{Fe}_{20} \mathrm{Co}_{2} \mathrm{ONi}_{41} \mathrm{Al}_{19}$ eutectic high entropy alloy with excellent tensile properties, Mater. Lett. 216 (2018) 144-146, doi:10.1016/j.matlet.2018.01.017.

[21] C. Ai, F. He, M. Guo, J. Zhou, Z. Wang, Z. Yuan, Y. Guo, Y. Liu, L. Liu, Alloy design, micromechanical and macromechanical properties of CoCrFeNiTa ${ }_{x}$ eutectic high entropy alloys, J. Alloy. Compd. 735 (2018) 2653-2662, doi:10.1016/j.jallcom.2017.12.015.

[22] Y. Tan, J. Li, J. Wang, M. Kolbe, H. Kou, Microstructure characterization of CoCrFeNiMnPd ${ }_{x}$ eutectic high-entropy alloys, J. Alloy. Compd. 731 (2018) 600611, doi:10.1016/j.jallcom.2017.09.057.

[23] W. Huo, H. Zhou, F. Fang, Z. Xie, J. Jiang, Microstructure and mechanical properties of $\mathrm{CoCrFeNiZr}_{\mathrm{x}}$ eutectic high-entropy alloys, Mater. Des. 134 (2017) 226-233, doi:10.1016/j.matdes.2017.08.030.

[24] H. Jiang, H. Zhang, T. Huang, Y. Lu, T. Wang, T. Li, Microstructures and mechanical properties of $\mathrm{Co}_{2} \mathrm{Mo}_{\mathrm{x}} \mathrm{Ni}_{2} \mathrm{VW}_{\mathrm{x}}$ eutectic high entropy alloys, Mater. Des. 109 (2016) 539-546, doi:10.1016/j.matdes.2016.07.113.

[25] F. He, Z. Wang, P. Cheng, Q. Wang, J. Li, Y. Dang, J. Wang, C.T. Liu, Designing eutectic high entropy alloys of $\mathrm{CoCrFeNiNb}_{\mathrm{x}}$, J. Alloy. Compd. 656 (2016) 284289, doi:10.1016/J.JALLCOM.2015.09.153.

[26] L. Jiang, Z.Q. Cao, J.C. Jie, J.J. Zhang, Y.P. Lu, T.M. Wang, T.J. Li, Effect of Mo and Ni elements on microstructure evolution and mechanical properties of the $\mathrm{CoFeNi}_{\mathrm{x}} \mathrm{VMo}_{\mathrm{y}}$ high entropy alloys, J. Alloy. Compd. 649 (2015) 585-590, doi:10.1016/j.jallcom.2015.07.185.

[27] T. Bhattacharjee, I.S. Wani, S. Sheikh, I.T. Clark, T. Okawa, S. Guo, P.P. Bhattacharjee, N. Tsuji, simultaneous strength-ductility enhancement of a nano-lamellar AlCoCrFeNi ${ }_{2.1}$ eutectic high entropy alloy by cryo-rolling and annealing, Sci. Rep. 8 (2018) 3276, doi:10.1038/s41598-018-21385-y. 
[28] S.R. Reddy, S. Yoshida, T. Bhattacharjee, N. Sake, A. Lozinko, S. Guo, P.P. Bhattacharjee, N. Tsuji, Nanostructuring with structural-compositional dual heterogeneities enhances strength-ductility synergy in eutectic high entropy alloy, Sci. Rep. 9 (2019) 1-9, doi:10.1038/s41598-019-47983-y.

[29] P. Shi, W. Ren, T. Zheng, Z. Ren, X. Hou, J. Peng, P. Hu, Y. Gao, Y. Zhong, P.K. Liaw, Enhanced strength-ductility synergy in ultrafine-grained eutectic highentropy alloys by inheriting microstructural lamellae, Nat. Commun. 10 (2019) 1-8, doi:10.1038/s41467-019-08460-2.

[30] O.N. Senkov, D.B. Miracle, K.J. Chaput, J.P. Couzinie, Development and exploration of refractory high entropy alloys-A review, J. Mater. Res. (2018) 1-37, doi:10.1557/jmr.2018.153.

[31] O.N. Senkov, S. Gorsse, D.B. Miracle, High temperature strength of refractory complex concentrated alloys, Acta Mater. 175 (2019) 394-405, doi:10.1016/J.ACTAMAT.2019.06.032.

[32] Q. Wei, G. Luo, J. Zhang, S. Jiang, P. Chen, Q. Shen, L. Zhang, Designing high entropy alloy-ceramic eutectic composites of $\operatorname{MoNbRe}_{0.5} \mathrm{TaW}(\mathrm{TiC})_{\mathrm{x}}$ with high compressive strength, J. Alloy. Compd. 818 (2020) 152846, doi:10.1016/j.jallcom.2019.152846.

[33] M. Zhu, L. Yao, Y. Liu, M. Zhang, K. Li, Z. Jian, Microstructure evolution and mechanical properties of a novel $\operatorname{CrNbTiZrAl}_{\mathrm{x}}(0.25 \leq \mathrm{x} \leq$ 1.25) eutectic refractory high-entropy alloy, Mater. Lett. 272 (2020) 127869 , doi:10.1016/j.matlet.2020.127869.

[34] Y. Lu, H. Jiang, S. Guo, T. Wang, Z. Cao, T. Li, A new strategy to design eutectic high-entropy alloys using mixing enthalpy, Intermetallics 91 (2017) 124-128, doi:10.1016/j.intermet.2017.09.001.

[35] H. Jiang, K. Han, X. Gao, Y. Lu, Z. Cao, M.C. Gao, J.A. Hawk, T. Li, A new strategy to design eutectic high-entropy alloys using simple mixture method, Mater. Des. 142 (2018) 101-105, doi:10.1016/J.MATDES.2018.01.025.

[36] X. Jin, Y. Zhou, L. Zhang, X. Du, B. Li, A new pseudo binary strategy to design eutectic high entropy alloys using mixing enthalpy and valence electron concentration, Mater. Des. 143 (2018) 49-55, doi:10.1016/j.matdes.2018.01.057.

[37] M. Wu, S. Wang, H. Huang, D. Shu, B. Sun, CALPHAD aided eutectic high-entropy alloy design, Mater. Lett. 262 (2020) 127175, doi:10.1016/j.matlet.2019.127175.

[38] O.N. Senkov, J.D. Miller, D.B. Miracle, C. Woodward, Accelerated exploration of multi-principal element alloys with solid solution phases, Nat. Commun. 6 (2015), doi:10.1038/ncomms7529.

[39] O.N. Senkov, J.D. Miller, D.B. Miracle, C. Woodward, Accelerated exploration of multi-principal element alloys for structural applications, CALPHAD Comput. Coupling Phase Diagr. Thermochem. 50 (2015) 32-48, doi:10.1016/j.calphad.2015.04.009.

[40] M.C. Gao, C.S. Carney, N. Doğan, P.D. Jablonksi, J.A. Hawk, D.E. Alman, Design of refractory high-entropy alloys, JOM 67 (2015) 2653-2669, doi:10.1007/s11837-015-1617-z.

[41] O.N. Senkov, C. Zhang, A.L. Pilchak, E.J. Payton, C. Woodward, F. Zhang, CALPHAD-aided development of quaternary multi-principal element refractory alloys based on NbTiZr, J. Alloy. Compd. 783 (2019) 729-742, doi:10.1016/j.jallcom.2018.12.325.

[42] N. Yurchenko, E. Panina, M. Tikhonovsky, G. Salishchev, S. Zherebtsov, N. Stepanov, A new refractory Ti-Nb-Hf-Al high entropy alloy strengthened by orthorhombic phase particles, Int. J. Refract. Met. Hard Mater. 92 (2020) 105322, doi:10.1016/j.ijrmhm.2020.105322.

[43] N. Yurchenko, E. Panina, M. Tikhonovsky, G. Salishchev, S. Zherebtsov, N. Stepanov, Structure and mechanical properties of an in-situ refractory $\mathrm{Al}_{20} \mathrm{Cr}_{10} \mathrm{Nb}_{15} \mathrm{Ti}_{20} \mathrm{~V}_{25} \mathrm{Zr}_{10}$ high entropy alloy composite, Mater. Lett. (2020) 127372, doi:10.1016/j.matlet.2020.127372.

[44] O.N. Senkov, S. Rao, K.J. Chaput, C. Woodward, Compositional effect on microstructure and properties of NbTiZr-based complex concentrated alloys, Acta Mater. (2018), doi:10.1016/j.actamat.2018.03.065.

[45] X. Yan, Y. Zhang, A body-centered cubic $\mathrm{Zr}_{50} \mathrm{Ti}_{35} \mathrm{Nb}_{15}$ mediumentropy alloy with unique properties, Scr. Mater. 178 (2020) 329-333, doi:10.1016/j.scriptamat.2019.11.059.

[46] O.N. Senkov, S.V. Senkova, C. Woodward, D.B. Miracle, Low-density, refractory multi-principal element alloys of the Cr-Nb-Ti-V-Zr system: microstructure and phase analysis, Acta Mater. 61 (2013) 1545-1557, doi:10.1016/j.actamat.2012.11.032.

[47] N.D. Stepanov, N.Y. Yurchenko, D.V. Skibin, M.A. Tikhonovsky, G.A. Salishchev, Structure and mechanical properties of the $\mathrm{AlCr}_{\mathrm{x}} \operatorname{NbTiV}(\mathrm{x}=0$, $0.5,1,1.5)$ high entropy alloys, J. Alloys Compd. 652 (2015) 266-280, doi:10.1016/j.jallcom.2015.08.224.

[48] N. Yurchenko, N. Stepanov, G. Salishchev, Laves-phase formation criterion for high-entropy alloys, Mater. Sci. Technol. (2017) 33 (United Kingdom), doi:10.1080/02670836.2016.1153277.

[49] O.N. Senkov, S. Rao, K.J. Chaput, C. Woodward, Compositional effect on microstructure and properties of NbTiZr-based complex concentrated alloys, Acta Mater. (2018), doi:10.1016/j.actamat.2018.03.065.

[50] O.N. Senkov, S.V. Senkova, C. Woodward, Effect of aluminum on the microstructure and properties of two refractory high-entropy alloys, Acta Mater. 68 (2014) 214-228, doi:10.1016/j.actamat.2014.01.029.

[51] C.M. Lin, C.C. Juan, C.H. Chang, C.W. Tsai, J.W. Yeh, Effect of Al addition on mechanical properties and microstructure of refractory $\mathrm{Al}_{\mathrm{x}} \mathrm{HfNbTaTiZr}$ alloys, J. Alloy. Compd. 624 (2015) 100-107, doi:10.1016/j.jallcom.2014.11.064.

[52] N.Y. Yurchenko, N.D. Stepanov, D.G. Shaysultanov, M.A. Tikhonovsky, G.A. Salishchev, Effect of $\mathrm{Al}$ content on structure and mechanical properties of the $\mathrm{Al}_{\mathrm{x}} \mathrm{CrNbTiVZr}(\mathrm{x}=0 ; 0.25 ; 0.5 ; 1)$ high-entropy alloys, Mater. Charact. 121 (2016) 125-134, doi:10.1016/j.matchar.2016.09.039.
[53] O.A. Waseem, U. Auyeskhan, H.M. Lee, H.J. Ryu, A combinatorial approach for the synthesis and analysis of $\mathrm{Al}_{\mathrm{x}} \mathrm{Cr}_{\mathrm{y}}$ MozNbTiZr high-entropy alloys: oxidation behavior, J. Mater. Res. (2018) 1-9, doi:10.1557/jmr.2018.241.

[54] B. Kang, T. Kong, H.J. Ryu, S.H. Hong, Superior mechanical properties and strengthening mechanisms of lightweight $\mathrm{Al}_{\mathrm{x}} \mathrm{CrNbVMo}_{\mathrm{N}}$ refractory high-entropy alloys $(\mathrm{x}=0,0.5,1.0)$ fabricated by the powder metallurgy process, J. Mater. Sci. Technol. (2020), doi:10.1016/j.jmst.2020.08.015.

[55] N.Y. Yurchenko, N.D. Stepanov, S.V. Zherebtsov, M.A. Tikhonovsky, G.A. Salishchev, Structure and mechanical properties of B2 ordered refractory AlNbTiVZr ( $\mathrm{x}=0-1.5$ ) high-entropy alloys, Mater. Sci. Eng. A 704 (2017) 82-90, doi:10.1016/j.msea.2017.08.019.

[56] H. Chen, A. Kauffmann, S. Seils, T. Boll, C.H. Liebscher, I. Harding, K.S. Kumar, D.V. Szabó, S. Schlabach, S. Kauffmann-Weiss, F. Müller, B. Gorr, H.J. Christ, M. Heilmaier, Crystallographic ordering in a series of Al-containing refractory high entropy alloys Ta-Nb-Mo-Cr-Ti-Al, Acta Mater. 176 (2019) 123-133, doi:10.1016/j.actamat.2019.07.001.

[57] S. Laube, H. Chen, A. Kauffmann, S. Schellert, F. Müller, B. Gorr, J. Müller, B. Butz, H.J. Christ, M. Heilmaier, Controlling crystallographic ordering in Mo-Cr-Ti-Al high entropy alloys to enhance ductility, J. Alloy. Compd. 823 (2020) 153805, doi:10.1016/j.jallcom.2020.153805.

[58] T.E. Whitfield, E.J. Pickering, L.R. Owen, C.N. Jones, H.J. Stone, N.G. Jones, The effect of $\mathrm{Al}$ on the formation and stability of a BCC - B2 microstructure in a refractory metal high entropy superalloy system, Materialia 13 (2020) 100858, doi:10.1016/j.mtla.2020.100858.

[59] N.Y. Yurchenko, N.D. Stepanov, A.O. Gridneva, M.V. Mishunin, G.A. Salishchev, S.V. Zherebtsov, Effect of $\mathrm{Cr}$ and $\mathrm{Zr}$ on phase stability of refractory Al-Cr-Nb-Ti-V-Zr high-entropy alloys, J. Alloy. Compd. 757 (2018) 403-414, doi:10.1016/j.jallcom.2018.05.099.

[60] S. Zherebtsov, N. Yurchenko, E. Panina, M. Tikhonovsky, N. Stepanov, Gum-like mechanical behavior of a partially ordered $\mathrm{Al}_{5} \mathrm{Nb}_{24} \mathrm{Ti}_{40} \mathrm{~V}_{5} \mathrm{Zr}_{26}$ high entropy alloy, Intermetallics 116 (2020) 106652, doi:10.1016/j.intermet.2019.106652.

[61] V. Soni, O.N. Senkov, J.P. Couzinie, Y. Zheng, B. Gwalani, R. Banerjee, Phase stability and microstructure evolution in a ductile refractory high entropy alloy $\mathrm{Al}_{10} \mathrm{Nb}_{15} \mathrm{Ta}_{5} \mathrm{Ti}_{30} \mathrm{Zr}_{40}$, Materialia 9 (2020) 100569, doi:10.1016/j.mtla.2019.100569.

[62] M.X. Zhang, P.M. Kelly, Edge-to-edge matching and its applications: part I. Application to the simple HCP/BCC system, Acta Mater. 53 (2005) 1073-1084, doi:10.1016/j.actamat.2004.11.007.

[63] D.B. Miracle, M.H. Tsai, O.N. Senkov, V. Soni, R. Banerjee, Refractory high entropy superalloys (RSAs), Scr. Mater. 187 (2020) 445-452, doi:10.1016/j.scriptamat.2020.06.048.

[64] Al-Nb (Aluminum-Niobium) Phase diagram, n.d.(2021)

[65] Al-ZrPhase Diagram - The Binary Al-Zr system [76Kub]+[62Poe], SpringerMaterials, 2021 (n.d.) https://materials.springer.com/msi/phase-diagram/docs/ sm_msi r 10 011474 01 full_LnkDia0 accessed August 26, 2020

[66] Cr-Zr (Chromium-Zirconium) Phase diagram, n.d. (2021)

[67] Cr-Nb (Chromium-Niobium) Phase diagram, n.d. (2021)

[68] B. Predel, Al-Cr (Aluminum - Chromium), Springer-Verlag, Berlin Heidelberg, 2006, doi:10.1007/10793176 84.

[69] B. Predel, Nb-Zr (Niobium-Zirconium), Springer-Verlag, Berlin Heidelberg, 1997, doi:10.1007/10522884_2210.

[70] Al-Ti (Aluminum-Titanium) Phase diagram, n.d. (2021)

[71] P. Franke, H.J. Seifert, eds., Binary System Cr-Ti:, (n.d.).(2021) doi:10.1007/9783-540-88142-1_17.

[72] Lazar Rokhlin, Nataliya Bochvar, Tatiana Dobatkina, Vasily Tomashik, Materials Science International Team, The Nb-Ti binary system, Mater. Sci. Int. (2015) Stuttgart https://materials.springer.com/msi/phase-diagram/docs/sm_msi_r_20_ 012723_01_full_LnkDia0

[73] B. Predel, Ti-Zr (Titanium-Zirconium), Springer-Verlag, Berlin Heidelberg, 1998, doi:10.1007/10551312_2847.

[74] L. Kaufman, H. Nesor, Theoretical approaches to the determination of phase diagrams, Annu. Rev. Mater. Sci. 3 (1973) 1-30, doi:10.1146/annurev.ms.03.080173.000245.

[75] S.A. Souza, C.T. Rios, A.A. Coelho, P.L. Ferrandini, S. Gama, R. Caram, Growth and morphological characterization of Al-Cr-Nb eutectic alloys, J. Alloy. Compd. 402 (2005) 156-161, doi:10.1016/j.jallcom.2005.04.137.

[76] F. Stein, C. He, I. Wossack, The liquidus surface of the Cr-Al-Nb system and reinvestigation of the $\mathrm{Cr}-\mathrm{Nb}$ and Al-Cr phase diagrams, J. Alloy. Compd. 598 (2014) 253-265, doi:10.1016/j.jallcom.2014.02.045.

[77] D.A. Abreu, A.A.A.P. Silva, J.C.P. Santos, D.F. Barros, C.S. Barros, N. Chaia, C.A. Nunes, G.C. Coelho, Liquidus projection of the Al-Ti-Zr system, J. Alloy. Compd. 849 (2020) 156463, doi:10.1016/j.jallcom.2020.156463.

[78] V.T. Witusiewicz, A.A. Bondar, U. Hecht, T.Y. Velikanova, Thermodynamic remodelling of the ternary Al-Cr-Ti system with refined Al-Cr description, J. Alloy. Compd. 644 (2015) 939-958, doi:10.1016/j.jallcom.2015.04.231.

[79] R. Elliott, Eutectic solidification, Int. Met. Rev. (1977) 161-186, doi:10.1007/BF02673701.

[80] C. Cui, C. Ren, Y. Liu, S. Wang, H. Su, Directional solidification of Fe-Al-Ta eutectic by electron beam floating zone melting, J. Alloy. Compd. 785 (2019) 62-71, doi:10.1016/j.jallcom.2019.01.158.

[81] Y.D. Wu, Y.H. Cai, T. Wang, J.J. Si, J. Zhu, Y.D. Wang, X.D. Hui, A refractory $\mathrm{Hf}_{25} \mathrm{Nb}_{25} \mathrm{Ti}_{25} \mathrm{Zr}_{25}$ high-entropy alloy with excellent structural stability and tensile properties, Mater. Lett. 130 (2014) 277-280, doi:10.1016/j.matlet.2014.05.134.

[82] O.N. Senkov, S.L. Semiatin, Microstructure and properties of a refractory highentropy alloy after cold working, J. Alloy. Compd. 649 (2015) 1110-1123, doi:10.1016/j.jallcom.2015.07.209. 
[83] L. Lilensten, J.P. Couzinié, L. Perrière, A. Hocini, C. Keller, G. Dirras, I. Guillot, Study of a bcc multi-principal element alloy: tensile and simple shear properties and underlying deformation mechanisms, Acta Mater. 142 (2018) 131-141.

[84] O.N. Senkov, A.L. Pilchak, S.L. Semiatin, Effect of cold deformation and annealing on the microstructure and tensile properties of a HfNbTaTiZr refractory high entropy alloy, Metall. Mater. Trans. A 49 (2018) 2876-2892, doi:10.1007/s11661-018-4646-8.

[85] S. Zherebtsov, N. Yurchenko, E. Panina, A. Tojibaev, M. Tikhonovsky, G. Salishchev, N. Stepanov, Microband-induced plasticity in a Ti-rich high-entropy alloy, J. Alloy. Compd. 842 (2020) 155868, doi:10.1016/j.jallcom.2020.155868.

[86] R.R. Eleti, N. Stepanov, S. Zherebtsov, Mechanical behavior and thermal activation analysis of HfNbTaTiZr body-centered cubic high-entropy alloy during tensile deformation at 77K, Scr. Mater. 188 (2020) 118-123, doi:10.1016/j.scriptamat.2020.07.028.

[87] S.I. Rao, B. Akdim, E. Antillon, C. Woodward, T.A. Parthasarathy, O.N. Senkov, Modeling solution hardening in BCC refractory complex concentrated alloys: NbTiZr, $\mathrm{Nb}_{1.5} \mathrm{TiZr}_{0.5}$ and $\mathrm{Nb}_{0.5} \mathrm{TiZr}_{1.5}$, Acta Mater. 168 (2019) 222-236, doi:10.1016/j.actamat.2019.02.013.

[88] L. Machon, G. Sauthoff, Deformation behaviour of Al-containing $C_{14}$ Laves phase alloys, Intermetallics 4 (1996) 469-481, doi:10.1016/0966-9795(96)00023-4.

[89] B. Zeumert, G. Sauthoff, Intermetallic NiAl-Ta alloys with strengthening Laves phase for high-temperature applications. I. Basic properties, Intermetallics 5 (1997) 563-577, doi:10.1016/S0966-9795(97)00031-9.

[90] G. Sauthoff, Multiphase intermetallic alloys for structural applications, Intermetallics 8 (2000) 1101-1109, doi:10.1016/S0966-9795(00)00045-5.

[91] O.N. Senkov, S.V. Senkova, D.B. Miracle, C. Woodward, Mechanical properties of low-density, refractory multi-principal element alloys of the $\mathrm{Cr}-\mathrm{Nb}-\mathrm{Ti}-\mathrm{V}-\mathrm{Zr}$ system, Mater. Sci. Eng. A 565 (2013) 51-62, doi:10.1016/j.msea.2012.12.018.

[92] N.D. Stepanov, N.Y. Yurchenko, E.S. Panina, M.A. Tikhonovsky, S.V. Zherebtsov, Precipitation-strengthened refractory $\mathrm{Al}_{0.5} \mathrm{CrNbTi}_{2} \mathrm{~V}_{0.5}$ high entropy alloy, Mater. Lett. (2017) 188, doi:10.1016/j.matlet.2016.11.030.

[93] J.P. Couzinié, L. Lilensten, Y. Champion, G. Dirras, L. Perrière, I. Guillot, On the room temperature deformation mechanisms of a TiZrHfNbTa refractory high-entropy alloy, Mater. Sci. Eng. A 645 (2015) 255-263, doi:10.1016/j.msea.2015.08.024.

[94] J.P. Couzinié, G. Dirras, Body-centered cubic high-entropy alloys: from processing to underlying deformation mechanisms, Mater. Charact. 147 (2019) 533-544, doi:10.1016/j.matchar.2018.07.015.
[95] S. Wei, S.J. Kim, J.Y. Kang, Y. Zhang, Y. Zhang, T. Furuhara, E.S. Park, C.C. Tasan, Natural-mixing guided design of refractory high-entropy alloys with as-cast tensile ductility, Nat. Mater. (2019) 1-7, doi:10.1038/s41563-020-0750-4.

[96] F. Maresca, C. Lee, R. Feng, Y. Chou, T. Ungar, M. Widom, K. An, J. Poplawsky, Y.C. Chou, P. Liaw, W. Curtin, Edge dislocations can control yield strength in refractory body-centered-cubic high entropy alloys, (2020). http://arxiv.org/abs/2008.11671 (accessed September 27, 2020).

[97] P. Kral, W. Blum, J. Dvorak, N. Yurchenko, N. Stepanov, S. Zherebtsov, L. Kuncicka, M. Kvapilova, V. Sklenicka, Creep behavior of an AlTiVNbZr high entropy alloy at 1073 K, Mater. Sci. Eng. A 783 (2020) 139291, doi:10.1016/J.MSEA.2020.139291.

[98] C. Lee, G. Kim, Y. Chou, B.L. Musicó, M.C. Gao, K. An, G. Song, Y.C. Chou, V. Keppens, W. Chen, P.K. Liaw, Temperature dependence of elastic and plastic deformation behavior of a refractory high-entropy alloy, Sci. Adv. 6 (2020) eaaz4748, doi:10.1126/sciadv.aaz4748.

[99] O.N. Senkov, J.P. Couzinie, S.I. Rao, V. Soni, R. Banerjee, Temperature dependent deformation behavior and strengthening mechanisms in a low density refractory high entropy alloy $\mathrm{Al}_{10} \mathrm{Nb}_{15} \mathrm{Ta}_{5} \mathrm{Ti}_{30} \mathrm{Zr}_{40}$, Materialia (2020) 100627, doi:10.1016/j.mtla.2020.100627.

[100] T. Sakai, A. Belyakov, R. Kaibyshev, H. Miura, J.J. Jonas, Dynamic and postdynamic recrystallization under hot, cold and severe plastic deformation conditions, Prog. Mater. Sci. 60 (2014) 130-207, doi:10.1016/j.pmatsci.2013.09.002.

[101] T. Takasugi, S. Hanada, M. Yoshida, High temperature mechanical properties of $\mathrm{C}_{15}$ Laves phase $\mathrm{Cr}_{2} \mathrm{Nb}$ intermetallics, Mater. Sci. Eng. A 192-193 (1995) 805-810, doi:10.1016/0921-5093(94)03319-6.

[102] A.V. Kazantzis, M. Aindow, I.P. Jones, G.K. Triantafyllidis, J.T.M. De Hosson, The mechanical properties and the deformation microstructures of the $C_{15}$ Laves phase $\mathrm{Cr}_{2} \mathrm{Nb}$ at high temperatures, Acta Mater. 55 (2007) 1873-1884, doi:10.1016/j.actamat.2006.10.048.

[103] M. Klimova, S. Zherebtsov, G. Salishchev, S.L. Semiatin, Influence of deformation on the Burgers orientation relationship between the $\alpha$ and $\beta$ phases in Ti-5Al-5Mo-5V-1Cr-1Fe, Mater. Sci. Eng. A 645 (2015) 292-297, doi:10.1016/j.msea.2015.08.008.

[104] S. Djanarthany, J.C. Viala, J. Bouix, An overview of monolithic titanium aluminides based on $\mathrm{Ti}_{3} \mathrm{Al}$ and $\mathrm{TiAl}$, Mater. Chem. Phys. (2001), doi:10.1016/S0254-0584(01)00328-5. 